\title{
1 || EL LIBELLUS APOLOGETICUS: UN SÍMBOLO DEL ENCICLOPEDISMO MEDIEVAL
}

\author{
Javier Vergara \\ Universidad Nacional de Educación a Distancia
}

Este trabajo presenta lo que puede considerarse la síntesis más acabada del enciclopedismo de la Baja Edad Media: el Speculum maius de Vicente de Beauvais, aunque no se trata tanto de presentar esta obra como de ofrecer la trascripción de su prólogo: el Libellus apologeticus que se presenta por primera vez en lengua castellana, ofreciendo una visión de conjunto del pensamiento del siglo XIII. El tema va precedido de un estudio sobre la gnoseología medieval y la presentación y proyección del Speculum maius.

\section{Gnoseología bajomedieval}

Uno de los hechos más significativos que define el pensamiento bajomedieval y más concretamente la cultura de los siglos XII y XIII es su misticismo racionalista, su anhelo de saber 1 . Una necesidad que el pensamiento de aquella época explicó desde una doble óptica de naturaleza psicológica y escatológica.

${ }^{1}$ El siglo XIII conforma con el siglo XII una unidad cultural que fue definida como el renacimiento cultural más importante de Occidente. Uno de los primeros investigadores que lanzó esta expresión fue HASKINS, $\mathrm{CH}$. H.; The Renaissance of the Twelfth Century. Cambridge Mass., 1927. Poco tiempo después aparecía publicado por PARÉ, G., BRUNET, A., TREMBLAY, P.; La renaissance du XII siècle. Les ecoles et l'enseignement. Paris, Publi. de l'institut d'etudes 
En el primero de los casos, el hombre culto de la Baja Edad Media entendió el entendimiento como la facultad humana por excelencia, su ornato más bello, su facultad superior. El hombre -dirán los escolásticos-, aunque se autoconquista, madura y se adquiere a sí mismo con la educación moral y el poder de la gracia, se actualiza con la fuerza del entendimiento [homo in quantum homo solus est intellectus]. Con él se captan las esencias de las cosas, se trasciende la materialidad de lo creado y se accede a la meta y razón última de la cultura: la búsqueda de la verdad o sabiduría ${ }^{2}$.

Esta apuesta no era original, los hombres de los siglos XII y XIII fueron fieles deudores de la psicología cognitiva grecorromana, del pensamiento paleocristiano y patrístico -especialmente agustiniano- y de la traducción, a finales del siglo XII, de la Metafísica de Aristóteles. Podría decirse que estos referentes casi colmaron por sí solos la sistematización de la gnoseología escolástica; sin embargo, no agotaron todas sus posibilidades. Hugo de San Víctor decía al respecto: "Hemos comprobado que los antiguos dijeron muchas cosas acerca de la naturaleza o ingenio, pero no hasta el punto que parezca que no ha quedado nada por decir» ${ }^{3}$. Faltaba una cosa muy importante por afirmar, cuyo honor sí cabe atribuir a la escolástica: sus artífices hicieron la síntesis más lograda y sistemática que hasta entonces se había hecho entre moral, ciencia y teología. Una síntesis que en el plano práctico derivó en un misticismo racionalista del que los escolásticos difícilmente pudieron sustraerse. Hugo de San Víctor, con una vehemencia inusitada, decía al respecto: «En efecto, una cosa es no saber y otra muy diferente no querer saber. No saber es, sencillamente, propio de la debilidad, pero despreciar el conocimiento es propio de una voluntad depravada» 4 .

Paralelamente a esta necesidad psicológica, la cultura bajomedieval añadió al conocimiento un matiz escatológico que fortaleció todavía más el culto racionalista que presidió buena parte de la cultura bajomebieval. Esta dimensión tiene mucho que ver con el concepto de naturaleza que a partir del siglo XII empezará a consolidarse en el occidente cristiano. Si para los antiguos la naturaleza era un concepto difuso y de difícil comprensión ${ }^{5}$, para los escolásticos se tornará claro y preciso. Una categoría que ya no será una

medievales, 1933. Estudios más recientes han ahondado en el significado renacentista de esta época. Especialmente significativo es el estudio de VERGER, J.; La renaissance du XII siècle. Paris, CERF, 1996. Un estudio sobre los límites y alcance de este término puede verse en SOTO RABANOS, J. Mª.; "Las escuelas urbanas y el renacimiento del siglo XII», en La enseñanza en la Edad Media. X Semana de Estudios Medievales, Nájera, 1999. Logroño, Instituto de Estudios Riojanos, 2000, pp. 207-243.

2 Boecio, en De consolatione philosophiae, 3, 10,1.37, sostenía: “De entre todas aquellas cosas a las que debemos aspirar, la primera es la sabiduría (sapientia), en la que reside la regla del bien perfecto".

3 Hugo DE SAN Victor, Didascalicon, I, X, 18. Edición promanuscrito de M.L. Arribas y C.Muñoz Gamero. Madrid, UNED, 2003.

4 Ibidem, I, I, 4.

5 Cicerón, De inventione. 1,34. 
entelequia incausada y ordenadora del universo -como la llamaba Platón en el Timeo-6, sino una creación divina cuya radicalidad más genuina será reflejar de forma indirecta, en su multiplicidad y singularidad formal, la voluntad, el sentimiento y el ser de Dios. Por eso conociendo la naturaleza, el mundo, el universo, se conocía a su creador y a su voluntad.

Esta apuesta por la refracción gnoseológica no era nueva, tenía una rancia tradición? ${ }^{7}$ Fue San Pablo, en la Primera Carta a los corintios, quien de modo explícito formuló la pertinencia didáctica de la refracción indirecta al afirmar: «vemos ahora mediante un espejo, confusamente; entonces veremos cara a cara» $(1 . C o r .13,12)^{8}$. Aunque serán los neoplatónicos y los Padres de la Iglesia, especialmente San Gregorio de Nisa y San Agustín, los que completarán los principios gnoseológicos del modo de conocer propio de la Alta Edad Media.

La refracción gnoseológica, a pesar de su importancia, no llegó a constituir un género literario hasta la Baja Edad Media. La serie de los espejos se inició con el Speculum ecclesiae, de Honorius Augustodinensis, escrito a comienzos del siglo XII, y con el Speculum virginum, anónimo que, aunque atribuido con frecuencia a Conrado de Hirsau, apareció en el año 1127. Con anterioridad a estas obras, el término speculum aparecía aisladamente sin constituir un género literario propio. Habrá que esperar al dinamismo gnoseológico y pedagógico del siglo XII para que la refracción adquiera carta de naturaleza didáctica con entidad propia y se aplique con profusión a diversas esferas, generando los libros-espejo más diversos. Entre los numerosos títulos, podemos señalar: Speculum fidei, de Guillaume de Saint Thierry, 11401144; Speculum regum, de Godofredo de Viterbo, 1183; Speculum universale, de Raoul Ardent, c. 1199; Speculum futurorum temporum, de Gébénon de Eberbach, c.1220; Speculum novitii, de Etienne de Sally, 1234; Speculum ecclesiae sive expositio missae, de Hugo Saint-Cher, 1248, etc.

Estas obras constituyeron un fiel exponente de la refracción gnoseológica de los siglos XII y XIII. En ellas se contienen dos de las ideas clave que en mayor medida definieron el concepto de naturaleza escolástico: por un lado, se trataba de una categoría con entidad propia, con sentido por sí misma y con una notable finalidad didáctica: sus formas particulares se presentaban como realidades entitativas y singulares capaces de explicar y dar sentido a la

${ }^{6}$ Platón, Timeo, 35 ab.

7 Cfr. JONSSON, E. M.: "Le sens du titre Speculum aux XIIe et XIIIe siècles et son utilisation par Vincent de Beauvais", en LOUSIGNAN, S.; Vincent de Beauvais. Intentions et receptions d'une oeuvre encyclopédique au Moyen-Âge. Cahiers d'etudes Médiévales. Cahier Spécial, 4, Paris, J. Vrin, 1990, pp. 11-33. Otro estudio que completa y refrenda las teorías sobre el conocimiento refractario de la realidad medieval es el de GRABES, H.; Speculum, Mirror und Looking-Glass, Kontinuität und originalität der Spiegelnaetapher in den Buchtiteln des Mittelalters und der englischen Literatur des 13. bis 17. Jahrhunderts. Tübiengen, 1973.

${ }^{8}$ Sobre la teoría de la refracción como forma de conocimiento en la antigüedad véase HUGEDE, N.; La métaphore du miroir dans les épîtres de saint Paul aux Corinthiens. Neuchâtel, 1957. 
existencia; por otro, su diversidad formal, en tanto que reflejo indirecto de la voluntad y sentimiento de Dios, se presentaba como el contenido óptimo y necesario para el perfeccionamiento y restauración de la naturaleza humana. Ideas que alentaron que el conocimiento (scientia) o aprendizaje (doctrina) alcanzara un valor escatológico y santificador de máximo reconocimiento. Su misión no era otra que actualizar el ser del hombre, destruir la rudeza intelectual del alma, acabar con la ignorancia causante de la desfiguración de la imagen de Dios en el hombre y sobre todo y especialmente conferir una forma indeleble en la medida que el saber sólo se desvanece en cuanto a la forma e imperfección, pero no en cuanto a su sustancia. Por eso, parafraseando a San Jerónimo, muchos escolásticos dirán: «aprendamos en la tierra la ciencia de aquello que perseverará con nosotros en el cielo" ${ }^{9}$. Máxima que llevará a los victorinos Hugo y Ricardo de San Víctor, y a otros escolásticos como Vicente de Beauvais, a afirmar que la restauración espiritual del hombre se operaba por la ciencia o doctrina ${ }^{10}$.

El misticismo racionalista que se deriva de esta tesis es evidente. Los escolásticos parecían -salvando distancias- sabios griegos redivivos que hacían del conocimiento, del saber y de la inteligencia los valores superiores del hombre. La aparición de las universidades, la emergencia progresiva de escuelas urbanas, el desarrollo de escuelas de gramática, el aumento de las migraciones intelectuales [Decretal Super Specula, 1219] y las reformas en pro de una mejor y mayor formación [IV Concilio de Letrán, 1215] fueron respuestas a un ambiente intelectual desconocido hasta entonces en Occidente11. Todo ello supuso un jaque importante a la cultura tradicional. A partir de ahora, los viejos límites de las artes liberales se presentaban poco menos que insuficientes para explicar la realidad de los nuevos tiempos. Abrir el conocimiento a la realidad de los nuevos saberes y a los métodos inductivos que se oteaban en el horizonte se presentaba como necesidad insoslayable de la que el enciclopedismo bajomedieval dio cumplida respuesta. Varios son los ejemplos que se hicieron eco de ese nuevo sentir, entre los más representativos sobresalen: De diversis artibus, del monje Theofilus (1130), Imago mundi, de Honorius Augustodinensis (1130), Summa de vitiis et virtutibus, de Raoul Ardent (1192-1193), De naturis rerum, de Alejandro de Neckham

${ }^{9}$ San Jerónimo, Epistolae, LIII, 9.

10 Vincentius Bellovacensis, Speculum doctrinale, lib. I, col. 2. Edición fotomecánica de la edición duacense de 1624. Graz-Austria, Akademische Druck-u. Verlagsanstalt, 1964. «et quoniam ipsa restitutio sive restauratio per doctrinam efficitur, atque perficitur». Esta idea se reflejó literalmente en el Didascalicon, VI, 14, de Hugo, y en el Liber excerptionum, I, I, 2 a 5, de Ricardo de San Víctor.

"La historiografía pedagógica se ha hecho eco abundante del nuevo orden educativo que supuso el renacimiento cultural de la Baja Edad Media. A título de síntesis se citan algunos títulos de especial significación con el tema: GUILLI, P.; Former, enseigner, eduquer dans l'Occident medieval 1100-1450. Paris, SEDES, 1999, 2 vols. VERGER, J.; Culture, enseignement et société en Occident aux XII et XIII siècles. Rennes, Presses Universitaires de Rennes, 1999. GENET, J.Ph.; La mutation de léducation et de la culture medievals. Occident chretien (XII siècle-milieu du XV siècle). Paris, Editions Sele Arslan, 1999; La enseñanza en la Edad Media. X Semana de Estudios medievales. Logroño, Instituto de Estudios Riojanos, 2000. 
(1203-1213), De proprietatibus rerum, de Bartholomeus Anglicus (12301240), De naturis rerum, de Tomás de Cantimpré (1244), Speculum maius (1244-1259), de Vicente de Beauvais, etc ${ }^{12}$.

\section{El Speculum maius}

Una de las obras que mejor sintetizó este nuevo sentir fue sin lugar a dudas el Speculum maius (1244-1259) del dominico de primera hora Vicente de Beauvais (1190-1264)13. Este trabajo constituye el punto de referencia obligado del espíritu enciclopedista y universal del siglo XIII y la obra por la que Vicente de Beauvais ha pasado a la posteridad ${ }^{14}$. No en balde, el dominico aspiraba a resolver un problema recurrente y perenne en el devenir de la cultura: proporcionar a sus coetáneos un reflejo auténtico y total de la ciencia. En el prólogo general del Speculum maius -más conocido como Libellus apologeticus - ya subraya esta idea cuando afirma que su propósito es mostrar, en un solo libro y como en un espejo, casi todo lo que en el mundo visible e invisible hay digno de investigación, imitación y admiración, desde el principio hasta el final dicho o hecho'5. A tal empresa le mueve solucionar un problema que en su época empezaba a ser palpable: seleccionar la información de una cultura cada vez más dinámica y productiva:

«La abundancia de libros, la escasez de tiempo y la fragilidad de la memoria no permiten retener por igual lo mucho que se ha escrito. Por eso a mí, el más humilde de los hermanos, rodeado siempre de libros de muchos autores, y que paso mucho tiempo leyéndolos, aconsejado además por mis superiores, me pareció oportuno com-

12 Cfr. MICHAUD-QUANTIN, P.; "Les petites encyclopédies du XIIIe siècle», en Cahiers d'Histoire Mondiale, 1966, IX, 3, pp. 580-596.

13 Vicente de Beauvais parece que vio la luz en los primeros años del reinado de Felipe Augusto, tomando algunos historiadores como fecha más aproximada de su nacimiento el 1190 . Nuestro protagonista se trasladó a París en busca de ciencia y títulos académicos hacia 1210. Allí ingresó en la recién fundada Orden de Predicadores, fundada en 1215. Estudió en la Universidad de París y hacia 1225 se sabe que fue enviado a consolidar la casa de Beauvais. Allí se dedicó al trabajo de investigación, al estudio de las Sagradas Escrituras, la predicación y la enseñanza de la teología. Su fama como predicador y hombre de letras trascendió los límites de su convento y sobre todo le abrió las puertas de la Corte de Luis IX de Francia. El monarca le llamó para predicar en la abadía cisterciense de Royaumont, fundada por el rey en 1228, cerca de París, en el Oise. Circunstancia que le posibilitó ser nombrado lector de la abadía real. Cargo que pudo desempeñar aproximadamente entre finales de 1246 y los últimos años de la década de los cincuenta. Su nombramiento es citado en tres de sus obras, fundamentales: en el prólogo del Liber consolatorius pro morte amici (1260), en el opúsculo sobre el Tractatus de morali principis institutione (1260/63) y en el prólogo del De Eruditione filiorum nobilium (1246/47). La fecha de su muerte no se conoce con exactitud, aunque se ha tomado como más probable 1264 .

${ }_{14}$ Un estudio sobre la estructura, génesis y proyección del Speculum maius puede verse en VERGARA CIORDIA, J.; "Vicente de Beauvais y el Speculum maius, 1244-1259", en LASPALAS, J (Ed.) Docencia y Formación. Pamplona, EUNSA, pp. 295-323.

15 Vincentius Bellovacensis: Libellus apologeticus. Edición fotomecánica de la edición duacense de 1624. Graz-Austria, Akademische Druck-u. Verlagsanstalt, 1964. Cap. III: De modo agendi \& titulo libri, col. 3, c. 
pendiar en una sola obra, ordenada y organizada de un modo determinado, un florilegio, elegido a mi criterio, de casi todos los libros que he podido leer, tanto de autores nuestros, es decir, doctores católicos, como de los gentiles (filósofos o poetas), o historiadores de unos y de otros ${ }^{16}$.

Para lograrlo, estructuró su trabajo en cuatro partes. En primer lugar aparece un prólogo, más conocido como Libellus apologeticus, en el que, a lo largo de 20 capítulos, expone los motivos y el fin de un trabajo que tiene en la comprensión y vivencia de las Sagradas Escrituras una buena parte de sus mejores empeños. A continuación viene el Speculum naturale, opúsculo que, siguiendo la técnica sancionada por San Ambrosio en el Hexamerón, describe los atributos divinos y los principios de la creación del mundo visible e invisible. El Speculum doctrinale conforma una tercera parte que cifra en la acción restauradora de la ciencia, la fe y la virtud los caminos o vías más adecuadas para cicatrizar las heridas causadas por el pecado original ${ }^{17}$. La obra se cierra con el Speculum historiale, opúsculo que recoge las vicisitudes de la humanidad desde Adán y Eva hasta 1254, en un intento por mostrar en las res gestae los registros de la salvación humana. A fines del siglo XIII, se le añadió arbitrariamente una quinta parte: el Speculum morale, que algunos atribuyeron incorrectamente al bellovacense por las conexiones que presenta con el Speculum doctrinale, cuando en realidad se trata de un trabajo posterior a la muerte de nuestro dominico.

Por su amplitud temática y su extensión material, el Speculum maius constituía todo un reto para su lectura, comprensión y difusión. Consciente de estas dificultades, y con el propósito firme de garantizar la unidad de su trabajo, Vicente optó por no presentar sus opúsculos simultánea o unitariamente sino como un libro por entregas en el que los tres espejos, a la vez que se concebían como unidades independientes y concatenadas, se contenían mutuamente. Para ello, al final del Speculum naturale, introdujo un resumen del historiale; y, al comienzo del historiale, situó un resumen conjunto del naturale y doctrinale. El Speculum doctrinale no contemplaba esta virtualidad por concebirse inicialmente como una parte del Speculum naturale. Esta estructura se completaba con índices alfabéticos de términos claves al final de cada opúsculo, con pequeños prefacios o prólogos particulares a cada speculum y con un prefacio general: el Libellus totius operis apologeticus, más conocido como Libellus apologeticus, y en el que, a modo de prólogo e introducción, nuestro polígrafo explica y presenta en 20 capítulos el sentido y los principios de su obra.

16 Libellus apologeticus, cap. I: De causa suscepti operis \& eius materia, col. 1, a-b.

17 Un estudio sobre el Speculum doctrinale puede verse en VERGARA CIORDIA, J. «El Speculum doctrinale de Vicente de Beauvais: un ideal prehumanista en la escolástica medievaln, en GONZALEZ GARCIA, M. (Ed.) La idea de Europa en el siglo XVI. Madrid, Universidad Nacional de Educación a Distancia, Col. Aula Abierta, pp.75-108. 
El primer Espejo, en el que se citan más de 350 autores, repartidos en 32 libros y 3736 capítulos, a lo largo de 1240 páginas folio -siempre en la edición duacense- es una descripción de la naturaleza desde una perspectiva filosófica y teológica. Comienza con un tratado sobre los atributos de Dios y la Trinidad beatífica, recreándose simbólicamente en la idea del cielo, la naturaleza de los ángeles, su jerarquía y su rebelión contra Dios. A continuación, y siguiendo la técnica sancionada por San Ambrosio en el Hexameronse refleja la creación del mundo visible e invisible, remarcando las propiedades de las cosas a lo largo de los seis días de creación. Por último, aparece la condición del primer hombre, mostrado como resumen y compendio de la creación, creado de la nada por voluntad divina y hecho a imagen y semejanza de Dios. En su descripción se hace hincapié en su dimensión física, espiritual y moral; se describe su estado beatífico y se acaba con el pecado original, sus consecuencias, los distintos tipos de pecado y los efectos propios de cada uno. Todo ello con un sentido descriptivo y simbólico, descubriendo en cada caso la idea de Dios ${ }^{18}$.

El Speculum doctrinale es una continuación del opúsculo anterior. Con 17 libros que contienen 2354 capítulos en 796 páginas folio, presenta un enfoque menos teórico y más cercano a la experiencia. Su fin es eminentemente pedagógico: trata de la reparación y restauración del hombre por acción de la ciencia, de la fe y de la virtud. El tema central gira en torno a la importancia del conocimiento y del estudio para cicatrizar las heridas causadas por el pecado original. Se abordan las virtualidades de todas las ciencias, desde la gramática hasta la teología, pasando por la lógica, la política, el derecho, la medicina y las artes mecánicas. En una palabra, Vicente se esfuerza en mostrar todo lo que hay que saber para comportarse convenientemente en la vida privada, familiar y social. Todo ello mezclado con las propiedades de la fe y de la virtud, soportes fundamentales del conocimiento que facilitan el acceso al ser, a la sabiduría y a la felicidad.

El Speculum historiale, narrado en forma anecdótica y con un fuerte sentido didáctico, contiene, en sus 1334 páginas folio, 32 libros y 3794 capítulos. La obra es un estudio cronológico de las vicisitudes de la humanidad desde Adán y Eva hasta 1254. En ella nuestro dominico reseña cronológicamente los acontecimientos más significativos de la historia sagrada y profana, entiéndase: la historia del pueblo judío, la sucesión de los imperios, de las monarquías y del papado; la biografía de autores célebres con citas de sus obras más representativas; los diversos Estados, sus gobernantes, sus guerras, sus revoluciones, etc. $\mathrm{Al}$ autor le preocupa especialmente recrearse en aquellos acontecimientos que han informado la fe cristiana, aquellos que demuestran la verdad histórica de dogmas cristianos negados por los paga-

18 Un estudio del Speculum naturale desde la perspectiva filosófica y teológica lo constituye la obra de BOURGEAT, J.B.; Etudes sur Vincent de Beauvais, Théologien, Philosophe, Encyclopédiste, ou Spécimen des etudes theologiques, philosophiques et scientifiques au moyen age, XIII $e$ siecle; 1210-1270. Paris, Auguste Durand Libraire, 1856. 
nos y herejes, y sobre todo extraer del conocimiento histórico instrucciones morales y edificantes. Planteamiento que refleja una concepción lineal e instrumental de la historia. Todo sucede y acontece para preparar la venida de Cristo y para que los imperios primero y las monarquías después sean sus principales valedores como corredentores seculares de Cristo ${ }^{19}$.

A fines del siglo XIII, se le añadió arbitrariamente una cuarta parte: Speculum morale, que algunos atribuyeron incorrectamente al bellovacense por las conexiones que presenta con el Speculum doctrinale ${ }^{20}$. El error fue aclarado definitivamente por los dominicos Quetif y Echard en 1719, que demostraron con claridad, mediante un estudio filológico y comparativo, que el Speculum morale no era una obra de Vicente de Beauvais, sino un trabajo posterior publicado a finales del siglo $\mathrm{XIII}^{21}$. Las razones que esgrimieron se basan en tres hechos incuestionables. En primer lugar, el Speculum morale presenta un planteamiento metodológico diferente al resto de los tres opúsculos. Mientras que el Speculum maius se estructura en libros y capítulos con continuas referencias bibliográficas, el Espejo moral se divide únicamente en tres libros sin capítulos, sin distinciones y sin referencias bibliográficas. En segundo lugar, no aparece recensionado, junto con los tres opúsculos del bellovacense, en los manuscritos de 1300 de los Catálogos de Antigüedades de la Sorbona, considerados una fuente muy reputada en la catalogación de autores y obras. Por último, la segunda parte del Speculum morale está tomada, en un porcentaje muy considerable, de tres fuentes: de la obra de Stephanus de Borbone, Los siete dones del Espíritu Santo, publicada en 1262; del Comentario de las Sentencias de Pedro de Tarentiso, aparecida en 1268; y de la Suma Teológica del Doctor Angélico. Circunstancia que llevó a algunos historiadores a pensar que quizá el Aquinate habría podido plagiar al bellovacense por reflejar el Espejo moral, casi con las mismas palabras, una parte muy considerable de la prima secundae y de la secunda secundae de la Suma de Tomás de Aquino22.

${ }^{19} \mathrm{Cfr}$. SCHMIDT-CHAZAN, M.; "L'idée d'Empire dans le Speculum historiale de Vincent de Beauvais", en LOUSIGNAN, S.; Vincent de Beauvais. Intentions et receptions d'une oeuvre encyclopédique au Moyen-Âge. Cahiers d'etudes Médiévales. Cahier Spécial, 4, Paris, J.Vrin, 1990, pp. 253-285.

20 El Espejo moral es una obra apócrifa que estaba acabada antes de 1297. En la Biblioteca de Boulougne-sur-Mer existe un manuscrito datado en ese año que contiene un Libellus apologeticus, anunciando un Speculum con cuatro opúsculos. Biblioteca de Boulougne-sur-Mer, Ms. $131, \mathrm{f}^{\circ} 388 v^{\circ}$. Véase PAULMIER-FOUCART Monique, "Étude sur l'état des connaissances au milieu du XIIle siècle: Nouvelles recherches sur la genèse du Speculum maius de Vincent de Beauvais", en Spicae, Cahiers de l'Atelier de Vincent de Beauvais, I, 1978, p. 103.

21 El primero en notar el carácter apócrifo del Speculum morale es el Padre J. Echard, a comienzos del siglo XVIII, en su trabajo: Sancti Thomae summa suo auctori vindicata, sive de V.F. Vicentii Bellovacensis scriptis dissertatio. Paris, 1708. Posteriormente, actualiz6 sus conclusiones en colaboración con J. Quetif, op. cit., pp. 215-218.

22 En 1304, Bernardo Guidonis, en De quatuor in quibus Deus Praedicatorum Ordinem, adjudicaba el Speculum morale a nuestro bellovaco. En 1473, J. Mentellus, en la edición de Estrasburgo, publicaba un Speculum maius con cuatro opúsculos. En 1494, Joannes Trithemius aceptaba el Espejo moral como un producto genuinamente bellovaco: De scriptoribus ecclesiasticis, Basel, Johannes de Amerbach, 1494, ff. 66-67. Los benedictinos de Douai alimentaron este error al incluir la obra, sin ninguna visión crítica, en la edición del Speculum 


\section{Proyección de la obra}

Una obra de esta naturaleza tendría por fuerza mayor que ser de gran utilidad. De ello estaba convencido nuestro polígrafo, que dedicó el capítulo IV del prólogo: De utilitate operis \& apologia auctoris a referirnos los beneficios espirituales y las ventajas materiales de su trabajo. Entre los primeros, señaló que el Speculum nacía para ayudarnos a alzar el corazón a Dios; y entre las ventajas: su obra suponía un tratado excepcional para la predicación, la lectura, la discusión y el aprendizaje mnemónico. Por eso la recomienda vivamente al mundo religioso, a los estudiantes y a los maestros ${ }^{23}$.

La obra no defraudó en absoluto. Su carácter enciclopédico caló con rapidez en la cultura medieval tardía que vio en la obra bellovaca y en la autoridad de sus excerpta un anclaje sólido para responder a los vaivenes políticos, bélicos, religiosos e incluso ideológicos que el alborear del Renacimiento empezaba tímidamente a plantear. De su difusión temprana nos da cuenta un compendio hagiográfico que se elabora en España hacia 1270-75 teniendo como base la obra bellovaca. De la misma época, data un esbozo de diccionario de autores cuyas noticias están extraídas en su mayor parte del Speculum historiale 24 . La influencia en autores medievales y renacentistas es otro ejemplo de su amplia difusión y calado. Ejemplos significativos son Geoffroy Chaucer y Cristina de Pisa. El primero, tomó a Vicente como base para elaborar, distintos estudios sobre la alquimia y la física ${ }^{25}$. La segunda, considerara a nuestro polígrafo maestro por excelencia en temas de virtud, su Libro sobre las tres virtudes está inspirado en el pensamiento bellovaco sobre la moral26. De igual modo, es manifiesta la influencia de Vicente en los

maius de 1624. Lewis Ellis Dupin lo sostenía con razonamientos en 1699: A New Ecclesiastical History, Londres, Abell Swalle, XI, V, p. 66. Incluso, después de los trabajos críticos de Quetif y Echard, algún autor despistado atribuyó en el siglo XIX el Speculum morale a Vicente de Beauvais. Véase: Françoise Antoine Delettre: Histoire du Diocese de Beauvais, depuis son établissement. Beauvais, Desjardins, 1842-43, II, pp. 320-322. Paternidad que también se encuentra en algún manuscrito. Concretamente B.L. Ullman cita dos manuscritos del Speculum morale atribuidos a Vicente de Beauvais. Véase: ULLMAN, B. L., "A Projet for a New Edition of Vincent of Beauvais", en Speculum, VIII, 1933, p. 326.

23 Sobre la utilidad del Speculum maius puede consultarse el trabajo de NADEAU, A.; "Faire oeuvre utile. Notes sur le vocabulaire de quelques prologues dominicains", en Lector et compilator, op. cit., pp. 77-97.

24 El compendio hagiográfico elaborado hacia 1270 es conocido por el manuscrito del Escorial 771. Del diccionario nos da cuenta VERNET, A.; "Une annotatio brevis quorumdam doctorum extraite du Speculum historiale de Vincent de Beauvais", en Scire litteras, Munich, S. Kramer y M. Bernhard eds. 1988, pp. 383-392. Estas citas pueden verse en uno de los estudios más completos realizados hasta ahora sobre la proyección de Vicente de Beauvais: SCHNEIDER, J.; "Vincent de Beauvais à l'épreuve des siècles", en Lector et compilator, op. cit., pp. 21-47.

$25 \mathrm{Cfr}$. AIKEN, Pauline; "Vincent of Beauvais and Chaucer's Monk's Tale", en Speculum, XVII, 1942, pp. 56-58; "Vincent of Beauvais and Chaucer's Knowledge of Alchemy", en Studies in Philology, XLI, 1944, pp. 371-389; "Vincent of Beauvais and the 'houres' of Chaucer's Physician", en Studies in Philology, LIII, 1956, pp. 22-24.

26 Cfr. GABRIEL, A.L.; "The Educational Ideas of Christine de Pisan", en Journal of the History of Ideas, 16, 1955. 
primeros renacentistas italianos ${ }^{27}$. Todo ello permite decir a Quetif y Echard que "hasta comienzos del siglo XVII, no se gastó otra enciclopedia más por el uso, ni tampoco hay otra más exquisita por los principios, de modo que se tenía como vocabulario universal o biblioteca íntegra, en la que todo que se buscase, estaba pronto y a mano" 28 . Astrik L. Gabriel en la misma línea afirma que "fue un best seller de la Edad Media (...) que tuvo un enorme éxito y una amplia influencia» en las ciencias teóricas y prácticas ${ }^{29}$.

Las numerosas copias que discriminadamente se hicieron de los diferentes opúsculos del Speculum maius corroboran su aceptación y amplia difusión. En el tomo IV de la publicación de Kaepelli-Panella: Scriptores Ordinis Praedicatorum Medii Aevi, se recoge una reseña de los manuscritos existentes en diferentes archivos y bibliotecas de Europa y Estados Unidos. Concretamente se reseñan 240 manuscritos del Speculum historiale, 50 del Speculum naturale y 20 del Speculum doctrinale 30 .

El Speculum historiale es a todas luces el opúsculo más difundido ${ }^{31}$. Mostrar el deveriir de la Historia, descansando en el papel rector de las monarquías vicarias de Cristo, contribuyó sin duda al éxito de su difusión. A la propia jerarquía eclesiástica y a la monarquía misma, aunque no fuera más que por razones prácticas, interesaba una visión sacralizada del poder que legitimara su autoridad por encima de cualquier opinión terrena. Ya, hacia 1268/71, Adam de Clermont, ante la amplitud material del Speculum historiale, hacía un resumen del mismo haciendo hincapié en la legitimación sacral del poder ${ }^{32}$. En la misma línea, aunque con claras concomitancias morales, Jean Hautfuney, hacia 1320, elaboraba para la guía moral y espiritual de los lectores un cuadro resumen muy aproximado y certero del Speculum historiale 33 . Paralelamente es importante reseñar las numerosas sinopsis y traducciones que se hicieron a lenguas vernáculas. En 1283, el poeta flamenco Jacob van Maerlant comienza a traducir a un dialecto

${ }^{29}$ Gabriel, A., op. cit. p. 101.

30 Cfr. KAEPPELI, TH.; Scriptores Ordinis Praedicatorum Medii Aevi, 4 vols. Roma, 1970-1993, vol. 4. El estudio de los diferentes manuscritos del Speculum maius fue iniciado en 1933 por ULLMAN, B. L., "A Projet for a New Edition of Vincent of Beauvais", en Speculum, VIII, 1933. Ullmam consignó al respecto cincuenta manuscritos completos del Speculum historiale, trece del Speculum naturale, siete del Speculum doctrinale, e incluso dos del apócrifo Speculum morale . Manuscritos que, en algunos casos, presentan la virtualidad de haberse transcrito en el mismo siglo XIII. Más recientemente, un estudio descriptivo amplio de diferentes manuscritos de nuestro polígrafo y especialmente del Speculum historiale ha sido realizado por STONES, Alisón, "Prolegomena to a Corpus of Vincent of Beauvais Illustrations», en LousignaN, S.: Vincent de Beauvais. Intentions et receptions d'une oeuvre encyclopédique au Moyen-Âge. Cahiers d'etudes Médiévales. Cahier Spécial, 4, Paris, J.Vrin, 1990, pp. 301-345.

31 Cfr. Duchenne, M. C.; Guzman, G. G. y VoorbIJ, J.B.; «Une liste des manuscrits du Speculum historiale de Vincent de Beauvais», en Scriptorium, 41, 1987, pp. 383-392.

32 Cfr. NADEAU, A.; "Deux abrégés du Speculum historiale par Adam de Clermont: les Flores historiarum et le Speculum gestorum mundi», en (Actes du XIV e Colloque de l'Institut d"Etudes Médiévales, Montreal, 1988), París, Saint-Laurent, 1990, pp. 375-389.

${ }^{33}$ Cfr. PAULmIER-FoucarT, M.; «Présentation et édition de la Tabula super Speculum historiale fratris Vicentii", en Spicae-Cahiers de l'Atelier Vincent de Beauvais, 2, 1980, pp. 19-203; 3, 1981, pp. 7-208. 
neerlandes y en verso algunas partes del Speculum historiale, en lo que se conoce como la primera traducción del Speculum a una lengua no latina. Trabajo que fue completado en 1316, alargando la historia hasta ese año ${ }^{34}$. En torno a 1328, Jean de Vignai realizó la primera traducción completa en lengua d'oïl, revisándose la obra en 1332 para ser ofrecida a Juana de Borgoña, reina de Francia y nieta de Luis IX. En 1495, Antonio Verard la imprimió en París, hecho que repitió en 1531 Nicolás Couteau. Aunque también fue traducida a otras lenguas: alemán, holandés y español35.

Pero el Espejo histórico no resumía por sí sólo la figura y la obra de Vicente de Beauvais. En el ocaso de la Edad Media y en el alborear de una secularidad profunda y racional las obras de este dominico de primera hora, lejos de relegarse al olvido o concitar polémicas, se presentarán como remanso de meditación y reflexión a la vez que se presentan como modelo de saber práctico para la educación moral y una guía de primer orden para el estudio y formación religiosa. No es extraño que, en el marco de ese sentimiento, los tórculos de la imprenta se hicieran eco en siete ocasiones de la edición completa del Speculum maius. Una de las ediciones más antiguas es la realizada en Estrasburgo por Johannes Mentelin, 1473-1476, que contenía el Speculum dividido en cuatro partes: naturale, doctrinale, historiale y morale. Casi en paralelo hay que computar una segunda edición, es la de A. Rus, editada igualmente en Estrasburgo entre 1473 y 1478 . La tercera, es la de Johannes Amerbach, impresa en Basilea en 1481 junto con la mayor parte de las obras conocidas de nuestro polígrafo. Entre 1483 y 1486, Antonio Koberger editó en Nurember la cuarta edición del Speculum, conteniendo los cuatro opúsculos que había consagrado la edición de J. Mentelin. A continuación vinieron las ediciones venecianas de $\mathbf{H}$. Liechtenstein, 1493-1494, y de D.Nicolini, 1590-1591. La última de las ediciones -y una de las más conocidas- es la editada por los benedictinos de Douai en 1624, en el taller de Balthazaris Belleri: Speculum quadruplex sive Speculum maius: naturale, doctrinale, morale, historiale.

34 Cfr. Biemans Jos A. A.S., "La tradition manuscrite du Spiegel historiael de Jacob van Maerlant. Étude de réception et archéologie du livre», en LOUSIGNAN, S.: Vincent de Beauvais. Intentions et receptions d'une oeuvre encyclopédique au Moyen-Âge. Cahiers d'etudes Médiévales. Cahier Spécial, 4, Paris, J. Vrin, 1990, p. 375. Un estudio más amplio sobre las traducciones del Speculum maius a lenguas medievales vernáculas es el trabajo de AERTs W.J. y otros, Vincent of Beauvais and Alexander the Great, Studies on the "Speculum Maius" and its Translations into Medieval Vernaculars, Groningen, E. Forsten, 1986.

35 La traducción castellana se trata de un estracto del Speculum historiale, concretamente de los libros XIII, XVI-XVIII, XX-XXII. Se titula: La Estoria de los quatro dotores de la Santa Eglesia. Véase en Catalogue General des libres imprimes de la Biblioteque Nationale. Paris, Imprimiere Nationale, 1972, vol. CCXI, p. 354. Algunas bibliotecas españolas guardan en sus anaqueles partes del Speculum historiale. Concretamente, en la Real Biblioteca del Escorial pueden verse diversos códices que recogen varios de los libros de este opúsculo: libros I-VII, códice latino O. I. 2; los índices de los libros VIII-XV, códice E.I.15; los libros XVI-XXVIII, códice O.I.3; los libros XXIV-XXXI, códice O.I.5. La biblioteca conserva también los libros IXXIV del Speculum naturale, códice O.I. 5. La descripción de estos documentos puede verse en ANTOLIN, G.; Catálogo de los códices latinos de la Real Biblioteca del Escorial. Madrid, Helénica, 1923. 
La edición duacense marcó el punto de inflexión de una etapa cultural que había tenido a Vicente de Beauvais como uno de sus puntos de referencia más cualificados. A partir de 1624 , la cultura europea ya no asentará tanto sus principios de acción en la escolástica ni en obras como el Speculum maius. Los presupuestos culturales de la llamada nueva ciencia aunque no condenarán al olvido a nuestro polígrafo sí lo relegarán a posiciones historiográficas postreras que llevarán su figura y su obra a una posición somnolienta y de letargo que el siglo XIX y sobre todo la segunda mitad del siglo XX se encargarán de revitalizar y actualizar.

El punto de inflexión en el interés por nuestro polígrafo tiene su origen en la entraña misma de la cultura renacentista. Nuestro dominico, por mucho que sus concepciones y presupuestos culturales adelanten posiciones humanistas, no puede sustraerse metodológica y culturalmente a ser un escolástico tardío para el que la historia de la humanidad no es más que el destino del pueblo de Dios caminando hacia la eternidad. Los humanistas no es que duden de que éste sea el fin del hombre; pero, enraizados en los presupuestos nominalistas de Abelardo, empezarán a retrotraer la historia al plano humano, poniendo su interés historiográfico no en lo profético o moral sino en el papel que la libertad individual ha jugado y desempeña en el destino de la humanidad. Esta vuelta al ciceronismo histórico, a la máxima de que la historia es magistra vitae, tendrá una preocupación manifiesta por la racionalidad humana y la seguridad metodológica de la misma. Aquí radica una de las grandes diferencias del humanismo renacentista con el otoño medieval de nuestro bellovaco que, si bien intuirá estos hechos, a él le interesará sobremanera mostrar la obra divina para mover, como si de una forma mecánica se tratara, la voluntad humana. El humanista, en cambio, pondrá su énfasis en la libertad individual y en la obra humana en cuanto protagonistas libérrimos del destino de la historia.

Este giro de la cultura está lejos de significar una negación u olvido de nuestro polígrafo, que alimenta muchas ideas humanistas que luego harán suyas pensadores de los siglos XV y XVI. No es extraño, por tanto, que el enciclopedismo bellovaco siga acarreando la admiración de eruditos e historiadores de esta época. Conrado Gesner, por ejemplo, en su Bibliotheca universalis (1545)36, le reservará un sitio de honor, y J.J. Scaliger (15161565), en su Scaligerana, se recreará alabando su erudición y conocimiento de las fuentes clásicas, amén de conocer y criticar las diversas ediciones del Speculum que se habían hecho en el siglo XV37.

El siglo XVI no fue una cultura monolítica, su diversidad entrañaba los inicios de un nuevo sentir donde la experiencia humana de la historia empe-

36 GESNER.C.; Bibliotheca universalis sive Catalogus omnium scriptorum locupletus... Zurich, 1545. Citado por ScHneIDER, J.; "Vincent de Beauvais à l'épreuve des siècles», en Lector et compilator, op. cit., p. 25.

37 Scaligerana, Colonia, 1667, p. 264. SCHNEIDER, J.; «Vincent de Beauvais à l'épreuve des siècles", en Lector et compilator, op. cit., p. 25. 
zaba a ser sometida a juicio y a crítica para confirmar su propia validez. Es el comienzo de la acribia intelectual y de la seguridad en el método, y es también el momento de las primeras críticas a nuestro dominico. Un ejemplo significativo nos lo ofrece el propio Erasmo que, en Elogio de la locura, ya desestima los métodos históricos bellovacos para interpretar las Sagradas Escrituras ${ }^{38}$. Una opinión semejante es la de nuestro Melchor Cano que, en sus Lugares teológicos (Salamanca, 1563), al comentar las relaciones entre teología e historia, critica severamente los relatos pueriles y milagreros que Vicente de Beauvais atribuye a la Virgen sin que exista ninguna seguridad histórica que los corrobore ${ }^{39}$. En la misma línea, Felipe Marnix de San Aldegondo ( $\dagger$ en 1598) se quejaba de que Vicente moviera a la piedad utilizando recursos como reliquias de plumas del Angel Gabriel, la lanza de San Miguel matando al dragón o el todavía conservado en vasijas especiales aliento del asno y del buey del portal de Belén ${ }^{40}$.

A partir del siglo XVII, estas críticas, que se enmarcan en un intento racionalista de la Reforma católica por dar solidez a los relatos y fuentes eclesiásticas, se harán extensivas a la exactitud y fiabilidad de otros relatos históricos. El milanés Tristano Calchi, en 1628, ya criticaba errores considerables en la datación histórica de las monarquías del Speculum historiale ${ }^{41}$; en la misma línea, G.J. Vossius (1577-1649) se quejaba de los serios problemas cronológicos contenidos en el Espejo histórico42; y el Padre L.E. Dupin (1657-1729) señalaba que el Speculum maius bellovaco sólo muestra la capacidad enorme de trabajo de Vicente de Beauvais pero no su buen gusto histórico o su capacidad de discernimiento ${ }^{43}$. Críticas que a la postre reducirán el interés por nuestro polígrafo relegándolo casi al olvido.

El siglo XVIII, con su racionalismo secular e inmanentista, apenas se hará eco de la obra bellovaca. El Speculum historiale ha dejado de tener interés y obras como el Diccionario histórico crítico de Pedro Bayle (1695-1697), la Historia eclesiástica de Fleury (1640-1723), los Diálogos históricos de Ignacio Jacinto Amat de Gravesón (1717-1722) y las Disertaciones e Historia de Natal Alejandro (1676-1686) marcarán sobremanera los referentes historiográficos. Nuestro bellovaco prácticamente estará en un eclipse, se relegará al olvido y cuando se cite, salvo honrosas excepciones, se hará para vituperarlo.

38 "Hic mihi stultam aliquam et indoctam fabulam ex Speculo, opinor, Historiali aut Gestis Romanorum in medium adferunt et eandem interpretantur allegorice, tropologice et anagogice» (Opera omnia, Desiderii Erasmi. t. III, Amsterdam- Oxford, 1979), p. 766. Citado por SCHNEmER, J.; "Vincent de Beauvais à l'épreuve des siècles», en Lector et compilator, op. cit., p. 25.

39 Ibidem, pp. 25-26.

40 Pasaje citado por M. Paulmier-Foucart y S. Lousignan: "Vincent de Beauvais et l'historie du Speculum maius n, en Journal des Savants, 1990, p. 214. Citado por SCNEIDER, J.; «Vincent de Beauvais à l'épreuve des siècles», en Lector et compilator, op. cit., p. 26.

41 Ibidem, p. 24.

42 Ibidem, p. 24.

${ }^{43}$ Nouvelle Bibliothèque des auteurs ecclésiastiques, t. X, Paris, 1702, pp. 70-71. Citado por SCHNEIDER, J.; „Vincent de Beauvais à l'épreuve des siècles», en Lector et compilator, op. cit., p. 27. 
Juan Carlos Brücker (1696-1770), desde la perspectiva sesgada de una filosofía antiescolástica, criticará con dureza la obra de Vicente afirmando que el bellovaco proyectó una imagen marchita de la filosofía y un tratamiento de la historia realizado desde una fe estrecha, para concluir afirmando que estamos ante un autor que extrae el agua de las fuentes pero no sabe beberla por lo que difícilmente puede ser de alguna utilidad44. Una honrosa y brillante excepción contemplará sin embargo el siglo de las luces: el estudio detallado, crítico y profundo del dominico J. Echard sobre la figura y la obra de Vicente de Beauvais, publicado en Scriptores Ordinis Praedicatorum recensiti, París, 1719. Este estudio, que se constituirá en un clásico de la historiografía bellovaca, apenas tendrá proyección fuera del ámbito de la orden dominica, y sólo los eruditos enciclopedistas de la Aufklärung alemana se harán eco del mismo. Albert Fabricius, por ejemplo, (1668-1736) considerará a Vicente el más sabio, el más fecundo y el más útil de los bibliógrafos de la historia45.

Pero el eclipse bellovaco de más de un siglo estaba pronto a su fin. El siglo XIX, al albur del nacimiento y desarrollo de la historia como ciencia, y el siglo XX, con su amplia apuesta por la especialización y diversificación del saber, reabrirán selectiva y discriminadamente el interés por la figura y la obra de Vicente de Beauvais. Muchos son los ejemplos que pueden traerse a colación. Por su carácter primigenio destaca Fortia de Urban, que, en 1819 , al estudiar la historia del conocimiento humano, considerará el Speculum maius el monumento más importante del mundo medieval ${ }^{46}$. Valentín Parisot, unos años más tarde, 1827, en la Bibliografía universal de Michaud, dirá que Vicente adelantó ideas a su siglo, fue un sabio ingenioso, un pensador profundo y un innovador reservado 47 . Pero a la nueva historiografía no le interesaba tanto Vicente de Beauvais como historiador general de la cultura sino su aportación singular e innovadora al devenir de la historia.

Una de esas innovaciones se encuentra precisamente en la historia del arte. A. Didron (1806-1867), uno de los promotores de las investigaciones arqueológicas francesas, considerará el Speculum maius el mejor exponente de la síntesis entre cronología, naturaleza y arte, siendo las estatuas de la catedral de Chartres el mejor reflejo de las intenciones bellovacas ${ }^{48}$. En la misma línea, Emile Mâle, en su estudio sobre el Arte religioso en el siglo XIII, 1899, considerará a nuestro bellovaco la guía de inspiración espiritual y religiosas más segura que tuvieron los artistas de las catedrales medievales, has-

44 Historia critica philosophiae, Leipzig, 1744, t. II, pp. 783-785. Citado por ScHNEIDER, J.; "Vincent de Beauvais à l'épreuve des siècles", en Lector et compilator, op. cit., pp. 29-30.

45 Bibliotheca graeca, Hamburgo, 1728. Citado por ScHNEIDER, J.; "Vincent de Beauvais à l'épreuve des siècles», en Lector et compilator, op. cit., p. 29.

46 Cfr. SCHNEIDER, J.; "Vincent de Beauvais à l'épreuve des siècles", en Lector et compilator, op. cit., p. 31.

47 Ibidem, p. 31.

48 Cfr. Iconographie chrétienne - Histoire de Dieu. Paris, 1843 (Coll. Doc. Inédits Histoire de France). Citado por SCHNEIDER, J.; «Vincent de Beauvais à l'épreuve des siècles», en Lector et compilator, op. cit., p. 32. 
ta el punto de afirmar que la catedral de Chartres es un suntuoso reflejo del Speculum maius ${ }^{49}$.

La ciencia natural también será deudora de las compilaciones bellovacas. M. Berthelot, en 1892, al estudiar la alquimia y los oficios técnicos de la Edad Media, considerará el Speculum naturale un modelo de referencia histórico por plantear serias críticas a los contenidos de las traducciones árabes ${ }^{50}$. El físico Pierre Duhem, autor de una importante obra sobre la historia de las ciencias físicas y astronómicas, vio en Vicente uno de los testimonios más representativos del renacimiento científico del siglo XIIII51. Y Lynn Thorndike, a pesar de apuntar serios errores en el saber científico de nuestro dominico, no dejó de reconocerle su considerable influencia en la historia de la física, astronomía, botánica y zoología 52 .

El mundo del derecho, especialmente la historiografía canónica, también se sentirá deudora de la obra bellovaca. Los libros VII, VIII, IX y X del Speculum doctrinale aportan citas del derecho romano y del derecho canónico, que gracias a Vicente han podido ser conocidas y conservadas. La historiografía canónica, en justa correspondencia, le reservará un lugar en los compendios y diccionarios canónicos del siglo $\mathrm{XX}^{53}$.

Muchas más citas, extraídas de la filosofía, de la teología, de la historia general y de la historia de la educación, podrían traerse a colación para confirmar el interés y la pervivencia de Vicente de Beauvais en la historiografía contemporánea. Baste sin embargo la referencia a dos acontecimientos cargados de significación histórica. El primero, el hecho revelador de que en 1964, con ocasión del séptimo centenario de la muerte de Vicente de Beauvais, volviera a reeditarse, en forma de edición fotomecánica, la edición duacense del Speculum maius de 162454 . Edición que ha vuelto a ser reeditada en 1992, en forma de microfilm, por la Biblioteca Apostólica Vaticana55. En segundo acontecimiento, se refiere a los boletines y encuentros científicos que mantienen viva su figura y su obra. Mención especial requiere el boletín

${ }^{49} \mathrm{Cfr}$. MALE, E.; L'art religieux du XIIIe siècle en France. T. III, Paris, 1899. Citado por SCHNEIDER, J.; “Vincent de Beauvais à l'épreuve des siècles», en Lector et compilator, op. cit., p. 37.

50 Cfr. Berthelot, M.; Histoire des sciences. La chimie au Moyen Âge. T. I, Paris, 1893, pp. 280289. Citado por Schneider, J.; "Vincent de Beauvais à l'épreuve des siècles", en Lector et compilator, op. cit., p. 35.

51 Cfr. DuhEm, P.; Le système du monde. T. III, Paris, 1958, pp. 346-349 Citado por SchneIder, J.; "Vincent de Beauvais à l'épreuve des siècles", en Lector et compilator, op. cit., p. 35.

52 Cfr. ThorNdike, L.; A History of Magic and Experimental Science, 8 vols, New York, Macmillan, 1923-58, vol. II, pp. 457-476. Otras denuncias de sus errores, reconociendo también sus aportaciones pueden verse en SARTON, G.; Introduction to the History of Science, 5 vols, Baltimor, William and Wilkins, 1927-48, vol. II, pp. 929-932.

53 Cfr. NAz, R.; Dictionnaire de droit canonique, t. VII, Paris, 1956, col. 1505-1507.

54 Vincentius Bellovacensis: Speculum quadruplex sive Speculum maius: naturale, doctrinale, morale, historiale. Edición Graz-Austria, Akademische Druck-u. Verlagsanstalt, 1964.

${ }^{55}$ Bibliotheca mundi seu Venerabilis Vincentii Burgundi (...) Speculum quadruplex, naturale, doctrinale, morale historiale. Biblioteca Apostólica Vaticana, Città del Vaticano, 1992. 
de información Vincent of Beauvais Newsletter, editado por la Universidad de Bradly en Estados Unidos. No menos significativo es también L'Atelier de Vicente de Beauvais, creado bajo el impulso de la Universidad de Nancy en cuyo seno ha surgido la revista Spicae que publica gran parte de las investigaciones actuales realizadas sobre nuestro polígrafo. Investigaciones que, a la vez que han motivado y posibilitado foros de debate y reflexión sobre la figura y la obra de nuestro dominico -el Coloquio de Montreal de 1988 y los Encuentros de Royaumont en 1995-, permiten recrearse en las ideas de uno de los personajes más sugerentes y atractivos de la cultura del bajo medievo.

\section{El libellus apologeticus}

El Libellus totius operis apologeticus, más conocido como Libellus apologeticus, constituye el prólogo e introducción en 20 capítulos -siempre en la edición duacense- de la obra bellovaca. Aquí nos limitamos a brindar su trascripción literal. Una transcripción cuyos contenidos son fiel exponente del sentir cultural de una buena parte de las gentes del saber de la Baja Edad Media. 


\section{Libellus Apologeticus}




\title{
OPUS PRAECLARUM
}

\author{
SPECULUM MAIUS
}

\section{N U N C U P A T U M \\ IN SPECULUM NATURALE, DOCTRINALE, MORALE ET HISTORIALE QUADRIPARTITUM, VINCENTII PRAESULIS}

\author{
INCHOAT NUMINE FOELICITATIS, AC PRIMO IN EAS PARTES \\ Generalis Prologus
}

\section{DE CAUSA SUSCEPTI OPERIS ET EIUS MATERIA}

Quoniam multitudo librorum, et temporis brevitas, memoriae quoque labilitas, non patiuntur cuncta, quae scripta sunt, pariter animo comprehendi. Mihi omnium fratrum minimo plurimorum libros assidue revolventi, ac longo tempore studiose legenti, visum est tandem (accedente etiam maiorum meorum consilio) quosdam flores pro modulo ingenii mei electos, ex omnibus fere quos legere potui, sive nostrorum, id est, Catholicorum Doctorum, sive Gentilium, scilicet Philosophorum et poetarum, et ex utrisque Historicorum, in unum corpus voluminis quodam compendio et ordine summatim redigere.

Ex his dumtaxat praecipue quae pertinere videntur, vel ad fidei nostrae dogmatis astructionem, vel ad morum instructione, sive ad excitandam charitatis devotionem, aut divinarum scripturarum mysticam expositionem, vel ad ipsius veritatis manifestam aut symbolicam declarationem; ut et studio meo quasi modum quendam imponens curiositati meae; caeterorumque nonnullorum forsitam mihi similium (quorum studium et labor est plurimos legere, eorumque flores excerpere) per hoc unum grande opus, utcumque satisfacerem, et laboris mei fructum poscentibus non negarem. Siquidem faciendi plures libros nullus est finis, et curiosi lectoris non satiatur oculus visu, nec auris impletur auditu.

\section{Ratio prima operis.}

Ad istud ipsum provocavit me plurimum falsitas vel ambiguitas quaterniorum, in quibus auctoritates Sanctorum adeo plerumque mendaciter a scriptoribus vel notariis intitulabantur cum scribebantur, ut quae esset sententia, vel cuius auctoris esset omnino nesciretur. Dum, verbi gratia, quae Augustini, vel Hieronymi erat, ascribebatur Ambrosio, vel Gregorio, vel Isidoro, vel e contra. Aut verborum aliqua parte dempta, vel addita, vel mutata, sensus auctoris corrumpebatur: sic et de dictis Philosophorum, aut Poetarum; sic de narrationibus Historicorum fiebat, dum unius nomen pro alio sumebatur, vel dictorum veritas simpliciter evertebatur. 
OBRA NOTABLE TITULADA

SPECULUM MAIUS

\title{
DIVIDIDA EN CUATRO PARTES: ESPEJO NATURAL, DOCTRINAL, MORAL E HITÓRICO DEL OBISPO VICENTE
}

\author{
LA ENCABEZA FELIZMENTE CON LA AYUDA DIVINA \\ PUESTO AL PRINCIPIO DE CADA UNA DE LAS PARTES UN \\ Prólogo General
}

\section{PRIMERA RAZÓN DE LA OBRA Y CONTENIDO DE LA MISMA}

La abundancia de libros, la escasez de tiempo y la fragilidad de la memoria no permiten retener por igual lo mucho que se ha escrito. Por eso a mí, el más humilde de los hermanos, rodeado siempre de libros de muchos autores, y que paso mucho tiempo leyéndolos, aconsejado además por mis superiores, me pareció oportuno compendiar en una sola obra, ordenada y organizada de un modo determinado, un florilegio, elegido a mi criterio, de casi todos los libros que he podido leer, tanto de autores nuestros, es decir, doctores católicos, como de los gentiles (filósofos o poetas), o historiadores de unos y de otros.

De estos libros tomé sobre todo lo referente a la demostración de los dogmas de nuestra fe, a la enseñanza de la moral, al ejercicio de la caridad, a la explicación piadosa de las Escrituras, o a la declaración real o simbólica de la verdad misma; para poner con mi trabajo como un cierto orden a mi curiosidad, satisfacer con esta obra extensa a otros muchos, cuyo trabajo, como el mío, consiste en leer libros y sacar lo importante de ellos, y no negar a quienes me lo pedían el fruto de mi trabajo. Ciertamente esta tarea de escribir libros nunca tiene fin, y ni el ojo del lector curioso se sacia con leerlos, ni su oído con oírlos.

\section{Primera razón de la obra.}

Me empujó muchísimo a ello la falsedad o ambigüedad de los códices, en los que la doctrina de los santos se cita tantas veces con error por los escritores o los notarios que las escribían, que ni se puede saber cuál es la sentencia, ni quién es su autor. Por ejemplo, lo que es de Agustín o Jerónimo se atribuye a Gregorio, Ambrosio o Isidoro; y al revés. $\mathbf{O}$ bien, quitando, añadiendo o cambiando algunas palabras, se altera el sentido del autor. Ocurre así con los escritos de filósofos y de poetas, o con las narraciones de los historiadores, tomando un nombre por otro, o sencillamente alterando la verdad de los escritos. 


\section{ITERUM ALIA CAUSA}

Videbam praeterea, iuxta Danielis prophetiam, temporibus nostris non tantummodo saecularium litterarum, verum etiam divinarum scripturarum ubique multiplicatam esse scientiam. Omnesque, praecipue fratres nostros, assidue sacrorum librorum historicis ac mysticis expositionibus, insuper et obscurioribus enodandis insistere.

\section{Ratio secunda.}

Inter haec autem historias ecclesiasticas (quarum lacte pascebatur antiquorum simplicitas) quodam modo viluisse, et in neglectum venisse; cum tamen non solum utique voluptatis ac recreationis spiritum, verum etiam aedificationis plurimum in se contineant.

\section{Infantia Ecclesiae.}

Eo quod primum quamdam Ecclesiae nascentis infantiam in Apostolis describebant, quos ipse Dominus tanquam mater filios, et tanquam gallina pullos sub alarum suarum deliciis educavit et fovit.

\section{Aetas provecta Ecclesiae.}

Deinde vero eamdem spiritus oris sui inductam, et quasi iam in robustiorem aetatem provectam, non solum in ipsis Apostolis, sed etiam in caeteris martyribus eorum cequacibus, per duadecim persecutionum tempora tribulationibus exposuit, eiusque patientiam in illis exercuit.

\section{Bella eius et triumphi.}

Post haec autem consummata victoria, scilicet, praedictorum Sanctorum, iamque pace per Constantinum Ecclesiae reddita, pullullantibus iterum diversis haeresibus, videlicet, Arriana, Novatiana, Pelagiana, et caeteris. Sicque ad rediviva bella ipsam Ecclesiam provocantibus; ut quam gladius non vicerat, verborum fallacia subverteret. Ipsos itidem haereticos per doctores suos catholicos, videlicet, Athanasium, Hilarium, Basilium, Ambrosium, Hieronymum, Augustinum, et caeteros, verbis et scripturis constanter revicit, eiusque saopientiam, ac si iam perfectae aetatis esset, in eis exacuit, et elimavit.

\section{Quieta Ecclesiae tempora.}

Deinde post huiusmodi triumphos Ecclesia quasi iam emerita in pace quievit, dum in sanctis Confessoribus, Anachoritis, et Monachis Aegypto et Syria caeterisque locis orbis philosophantibus, ad coelestem et contemplativam vitam ascendit, simulque conversationem ducens angelicam, infinita bene vivendi uberrima exempla reliquit.

Haec et alia plurima in illis historicis utilia simul et delectabilia cernens, plurimosque fratrum nostrorum huiuscemodi rerum ignaros conspiciens, ipsas etiam sicut et caetera de diversis auctoribus diligenter excerpendo collegi, atque ad certum ordinem temporum cuncta redegi. 


\section{UNA SEGUNDA RAZÓN}

Veía yo además que, según la profecía de Daniel, en nuestro siglo se había multiplicado no sólo el estudio de las letras mundanas, sino también de las Sagradas Escrituras; y que todos, en especial nuestros hermanos, insistían en exposiciones históricas y místicas de los libros sagrados, y sobre todo en interpretar las cuestiones más oscuras.

\section{Segunda razón.}

Entre tanto, las historias eclesiásticas, de cuya leche se nutría la sencillez de los antiguos, se habían como envilecido y casi abandonado, cuando en ellas no sólo hay espíritu de gozo y distracción, sino también de edificación.

\section{Infancia de la Iglesia.}

Primero indicaban cierto candor de la iglesia naciente en los apóstoles, a los que el mismo Señor educó y protegió como una madre a sus hijos, y como una gallina a sus polluelos bajo el amparo de sus alas.

\section{Edad madura.}

Luego, guiada con la virtud de su espíritu, y cuando ya había alcanzado la edad madura, la expuso a tribulaciones durante doce años de persecuciones, no sólo en los propios apóstoles, sino en los otros mártires que les siguieron, y probó en ellos su paciencia.

Sus guerras y triunfos.

Después de esto, consumada la victoria de los santos, y devuelta la paz a la Iglesia por medio de Constantino, aparecieron de nuevo distintas herejías, como la Arriana, Novatiana, Pelagiana, etc. Estas despertaron en la propia Iglesia viejas guerras, de manera que a la que no había vencido la espada, la trastornó la falacia de las palabras. A los herejes los refutó tenazmente con escritos y sermones de sus doctores católicos, Hilario, Basilio, Ambrosio, Jerónimo, Agustín, y otros; y aguzó contra ellos y pulió, como si ya fuera mayor de edad, su sabiduría.

\section{Tiempos de paz.}

Finalmente, después de estos triunfos gozó de una merecida paz, a la vez que en sus santos confesores, anacoretas, monjes filósofos en Egipto y en Siria, y en el resto del mundo, se elevó a una vida celeste y contemplativa; y con una convivencia angelical dejó innumerables ejemplos fecundísimos de una vida santa.

Viendo yo muy útiles estas cosas y muchas otras de aquellas historias, a la vez que divertidas, y observando que muchos de nuestros hermanos desconocían esta clase de temas, los recogí, tomándolos cuidadosamente de distintos autores, y los ordené con arreglo a un determinado orden cronológico. 


\section{DE MODO AGENDI ET TITULO LIBRI}

Cum autem apud me sollicite ac studiose inquirerem, quonam modo vel ordine cuncta in unum corpus aptius compingerem, cernens quod si diversorum sententias ad eandem materiam pertinentes (ut fieri solet) per singulos titulos annotarem, verbi gratia, sub uno titulo sententias et exempla de Charitate, sub alio de Castitate, et sic de caeteris virtutibus et vitiis sigillatim tractando procederem, totam utique rerum naturam (quam nihilominus describere diligenter disposui) necessario ab hoc opere non excluderem, necnon et ordinem totius historiae non parum utilitatis et pulchritudinis habentem, omnino confunderem et everterem; consideratis omnibus, competentiorem procedendi modum nullatenus reperi, quam istum, quem prae cunctis elegi, videlicet, ut iuxta ordinem sacrae Scripturae, primo de Creatore, postea de creaturis, postea quoque de lapsu et reparatione hominis, deinde vero de rebus gestis iuxta seriem temporum suorum ordinate dissererem. In fine vero totius operis singulas eius particulas ad idem pertinentes per singulas materias quibusdam titulis et notulis concordarem.

Denique quoniam (ut superius dictum est) ex diversis auctoribus hoc opus contextum est, ut sciatur quid cuius sit, singulorum dictis eorum nomini annotavi, ac ne facile transponerentur de locis propriis, nequaquam in margine, sicut fit in Psalterio glossato, et epǐstolis Pauli, et in sententiis, sed inter lineas ipsas (sicut fecit Gratianus in compilatione canonum) ea inserui.

Autoris vox sapere petita in his libris quid significat.

Interdum etiam ea quae ipsa vel a maioribus meis, scilicet modernis doctoribus, didici, vel in quorumdam scriptis notabilia repperi, nomine meo, id est, auctoris intitulavi. Illud autem lectorem non lateat, nonnulla in hoc opere, maxime quae de gestis sanctorum Martyrum et Confessorum, non ita penitus abbreviata esse, uti volui, quia nimirum aliis quoque studiis per obedientiam interdum occupatus et intentus, non omnia manu propria, sed pleraque per manus notariorum abbreviavi, ut potui. Verumtamen hoc nihilominus attendat, quod nimis abbreviata narratio legenti, vel audienti minus sapiat.

\section{Ratio nominis horum librorum.}

Ut autem huius operis partes singulae lectori facilius elucescant, ipsum totum opus per libros, et per capitula distinguere volui, quod et Speculum Maius appellari decrevi. Speculum quidem eo quod quicquid fere speculatione, id est, admiratione vel imitatione dignum est, ex his quae in mundo visibili et invisibili ab initio usque ad finem facta, vel dicta sunt, sive etiam adhuc futura sunt, ex innumerabilibus fere libris colligere potui, in uno hoc breviter continentur. Maius autem ad differentiam parvi libelli iamdudum editi, cuius titulus est Speculum, vel imago mundi, in quo, scilicet, huius mundi sensibilis dispositio et ornatus verbis describitur.

\section{DE UTILITATE OPERIS ET APOLOGIA AUCTORIS}

Itaque cum hoc agerem non ignorans plerosque longitudines voluminis postmodum, cum iam perfectum foret, nimium abhorrere, sciens tamen utilitatem, nolui penitus ab opere coepto desistere, donec illud (iuvante Deo) ad finem producerem. Certus sum enim, et confido in Domino, hoc ipsum opus non solum mihi, sed omni studiose legenti, non parum utilitatis afferre, non solum ad Deum per 


\section{DEL MODO DE ELABORACIÓN DEL LIBRO Y DE SU TITULO}

Considerando yo con inquietud e interés cómo y en qué orden reuniría mejor todas las anotaciones en un solo cuerpo, viendo que si juntaba las sentencias de muchos pertenecientes a una materia, como se suele hacer, por títulos separados, por ejemplo, bajo un título las sentencias y ejemplos sobre la caridad, bajo otro los de la castidad, y procedía así tratando una por una todas las virtudes y los vicios, abarcaría en esta obra toda la naturaleza (que yo me había propuesto describir puntualmente), pero a la vez mezclaría y rompería el orden, tan útil y hermoso, de toda la historia; después de estas consideraciones, no encontré otro procedimiento mejor que éste que elegí, a saber, seguir el orden de las Sagradas Escrituras, y tratar primero del Creador, luego de las criaturas, de la caída del hombre y de su reparación; después, de los hechos históricos, ordenados en la sucesión de los tiempos. Al final de la obra reuniría bajo determinados títulos y notas todos sus apartados según cada una de las materias.

Finalmente, como esta obra, dije antes, recoge lo de diversos autores, para que se conozca bien lo que es de cada uno, anoté sus nombres junto a sus dichos. Y para que no se cambiaran fácilmente de su lugar propio, no los puse en el margen, como se hace en el Salterio glosado, en las epístolas de S. Pablo y en las sentencias, sino que los intercalé en el texto, como hizo Graciano en la compilación de los cánones.

Lo que en estos libros significa la expresión del autor 'sapere petita'.

A veces, lo que aprendí de mis mayores, es decir, de los doctores modernos, o lo que hallé más notable en los escritos de algunos, lo puse bajo mi nombre, como autor. Sepa también el lector que algunos apartados en esta obra, máxime los que tratan hechos de los santos mártires y confesores, no han sido abreviados como yo quise, porque ocupado y metido en otros quehaceres por obediencia, no resumí todo por mi propia mano, sino que casi siempre me valí, como pude, de notarios. Mirad, no obstante, que quien oye o lee una cosa muy resumida, la saborea menos.

\section{Razón del título de la obra.}

Para que el lector distinga mejor cada parte de esta obra, decidí dividirla toda en libros y capítulos, y llamarla Speculum Maius. Speculum, porque en ella se encierra cuanto es digno de contemplación, esto es, de admiración o imitación, que se ha hecho, o dicho, o que va a suceder, desde el principio hasta el fin, en el mundo visible y en el invisible, y que pude extraer de libros casi incontables. Maius, a diferencia de otro librito editado antes con el título de 'Speculum' o imagen del mundo, en que se describe con pocas palabras la disposición y ornato de este mundo sensible.

\section{UTILIDAD DE LA OBRA Y APOLOGIA DEL AUTOR}

Aunque al escribir esta obra sabía yo que ampliarla demasiado haría que muchos, una vez terminada, la rechazaran, consciente, no obstante, de su utilidad, no quise de ninguna manera dejar el trabajo iniciado hasta llegar, con la ayuda de Dios, a su final. Estoy seguro, y tengo fe en el Señor, que esta obra será de gran utilidad, no sólo a mí, sino a cualquiera que la lea con interés, para conocer a Dios por sí 
se, et creaturas visibiles et invisibiles cognoscendum, ac per hoc diligendum, et cor suum in devotione charitatis multorum doctorum ignitis sententiis et exemplis excitandum, verum ad praedicandum, ad legendum, ad disputandum, ad solvendum, necnon et generaliter ad unumquemque fere modum et genus artis cuiuslibet clare explicandum.

Opus non antiquum, breve, longum.

Porro ne quis in hoc opere vel de novitate, vel de nimia prolixitate me aestimet arguendum, quoniam hoc ipsum opus novum quidem est simul et antiquum, breve quoque pariter et prolixum. Antiquum certe auctoritate et materia. Novum vero partium compilatione, et earum aggregatione. Breve quoque propter multorum dictorum in breve perstrictionem. Longum nihilominus propter immensam materiae multitudinem.

Denique si pauca ex ipsis minimis particularibus voluminibus, ex quorum flosculis hoc ipsum opus universale contextum est, precio compararem, aut scribi facerem, (quorum tamen magnitudo forsitam huic operi, vel maiori parti per aequiparantiam respondere posset, verbi gratia ex philosophis, Aristotelem de animalibus, Avicennam de medicina, Plinium de historia naturali, vel ex Iudaeis Iosephum, ex nostris autem Augustinum de civitte Dei, vel super Psalterium, vel super Ioannem, Moralia quoque beati Gregorii, vel aliquem huiusmodi) nullus esset fortassis, qui argueret, nemoque reprehenderet; et tamen cum haberem haec omnia, ne dicam tertiam, ver quartam, immo nec saltem decimam, aut vicesimam partem eorum utilium, quae in hoc opere continentur in scriptis possiderem, aut tenerem.

Nam ex ipsis certe libris, quos etiam sacri doctores, olim in exponendis scripturis, aut in refellendis haereticis, sive quibuslibet aliis emergentibus causis utiliter ediderunt, dum quisquam quoquam legitur, plerumque vix in tribus, aut quatuor, vel quinque capitulis sententia notabilis ad proferendum in publico sermone, sive etiam in lectione vel disputatione reperitur. Quantum minus ergo nunc arguendus videor, quia multorum librorum florem quendam atque medullam in unum volumen compegi: iterumque sub certis titulis ordine congruo redegi.

\section{APOLOGIA DE REGNIS ET BELLIS HUIC OPERI INSERTIS}

Ut autem utilitas operis plenius innotescat, taceo de virtutibus, et vitiis et sacramentis, et caeteris huiuscemodi, quae ad aedificationem morum, ac fide evidentius pertinent, et quorum utilitates per se patent. Etiam ea quae minoris hic utilitatis, immo quasi superflua penitus esse videntur (ut sunt ea quae de regnis et bellis, ac caeteris huiusmodi enarrantur) attentius consideranti, utilia satis esse probantur.

Nam et historiae non solum gentilium, sed ecclesiasticae et etiam evangelicae, secundum Imperatorum et Regum tempora describuntur. Lucas namque cum incarnationis Dominicae historiam texeret, in ipso Evangelii sui principio, de Herode rege, et post pauca, de Caesare Augusto mentionem fecit: ut illa quae minus nota erant hominibus, ab his quae pene apud omnes fama celebri ferebantur, confirmarentur et roborarentur. Illae quippe res gestae, ut dicit Hugo Floriacensis, quae nulla regum ac temporum certitudine commendantur, no pro historia recipiuntur. 
y por sus criaturas, visibles e invisibles, y amarlo y alentar en el corazón el fuego de la caridad con los ejemplos y sentencias sublimes de numerosos doctores; o bien para predicar, leer, disputar, resolver, e incluso para explicar en general de una forma clara cada modalidad y género de cualquier arte.

No es obra antigua, ni breve, ni extensa.

Nadie piense, además, en tildar esta obra de nueva o de extensa, porque es a la vez nueva y antigua, y es al mismo tiempo, extensa y breve. Es antigua por su autoridad y su contenido, y nueva por el inventario y agrupación de sus partes. Es breve por el resumen que hace de muchos textos, y extensa por la inmensa cantidad de materia.

En fin, si yo comprara por su precio, o los mandara escribir, unos pocos de esos volúmenes particulares, con cuyas sentencias más célebres se ha elaborado esta obra universal (y que juntos pudieran tener la misma extensión que toda esta obra, o de su mayor parte: de los filósofos, por ejemplo, el tratado de Aristóteles sobre los animales, o el de medicina de Avicena, o la Historia Natural de Plinio; de los Judíos a F. Josefo; de los nuestros, a S. Agustín con La Ciudad de Dios, o sus comentarios a los Salmos o a S. Juan; o bien de S. Gregorio los Tratados Morales; y alguno más así) no habría nadie, quizás, que me acusara o reprendiera. Sin embargo, aun poseyéndolos todos, no tendría ni la tercera, o la cuarta, o la décima, ni la vigésima parte de los útiles que han sido empleados en la confección de esta obra.

Si incluso de los propios libros que escribieron en su tiempo los doctores sagrados para exponer las Escrituras, refutar las herejías, o por otros motivos de emergencia, cuando alguien lee alguno, en tres, cuatro o cinco capítulos apenas si encuentra alguna sentencia notable para citarla en un sermón, en una lección, o en una conversación, tanto menos creo yo merecer que se me reprenda por haber recogido en una sola obra lo más selecto y la médula de muchos libros, y de haberlo organizado congruentemente bajo unos títulos determinados.

\section{JUSTIFICACIÓN DE LOS REINOS Y LAS GUERRAS RECOGIDAS EN ESTA OBRA}

Para que destaque más la utilidad de la obra, no hablo de las virtudes, los vicios, los sacramentos, y otros temas relacionados claramente con la moral o con la fe, cuyos beneficios son patentes por ellos mismos. Aquellas cosas incluso que parecen tener aquí menos utilidad, o hasta ser superfluas (como historias de reinos y guerras, y similares) si bien se miran, se ve que son muy útiles.

Las historias, tanto paganas como eclesiásticas, y también las evangélicas, se narran siguiendo los tiempos de reyes y emperadores. Cuando Lucas cuenta la historia de la encarnación del Señor al principio mismo del Evangelio, habla del rey Herodes, y poco después de César Augusto, de manera que aquellos hechos menos conocidos para los hombres queden asegurados y reforzados con estos datos que son conocidos por casi todos. "Aquellas gestas» dice Hugo Floriacense "que no están avaladas con datos ciertos de la época y de los reyes, no se tienen por históricas" 
Valet igitur in hoc opere successionis temporum et annorum Regum, et Imperatorum, necnon Romanorum Pontificum annotatio brevis. Nec solum ad prasentis historiae, verum etiam ad cuiuslibet alterius nomen Imperatoris, vel Papae, vel Regis sub quo gesta sit, habentis confirmationem et elucidationem: ut scilicet, si dubitetur de tempore hoc, ad catalogum regum illius terrae, in qua res illa gesta refertur, recurri possit, ibique reperiatur quo tempore Rex ille regnaverit, ac per hoc etiam quo tempore illa gesta sit.

Verum tamen, quia de annorum numero multa est in historiis dissonantia, nulli reor precise ac penitus adhaerendum, maximeque numero Chronicarum. Sed ad tantum valet ut sciatur, no quo anno, sed quo tempore, vel sub quo Imperatore quaeque res annotata acciderit.

Pia meditatio de roeliis paganorum.

Caeterum ex bellis famosis usquequaque per orbem intra diversa regna commissis, antequam veniret Rex noster pacificus, qui locutus est pacem in plebem suam, lector animadvertere poterit quanto fervore pugnandum sit nobis contra spirituales hostes pro saluti nostra spirituali et aeterna gloria nobis promissa: cum illi quidem, utpote infideles, huius salutis et gloriae ignari, ac penitus exortes, tam acriter dimicaverunt pro salute temporali tantum et gloria momentanea, vel adipiscenda, vel tuenda.

Ex caede quoque hominum in eisdem proeliis innumerabili perpetrata, licet advertere severitatem Dei in reprobos: quos quasi pecora vilia inutiles vel abiectos reputans, peccatis eorum exigentibus, tot eorum milia, tanquam innumerabiles multitudines, in singulis fere bellis, per manus hostium interire, simulque in anima et corpore passim perire permisit.

E contra vero bonitatem ipsius, et clementiam in electos, pro quibus ipsemet in fine temporum Rex Israël, mutato habitu suo, ne agnosceretur ab hostibus, id est, forma servi suscepta, armis nostrae mortalitatis indutus, ut quod infirmum est Deo fortius esset hominibus, in campum certaminis huius mundi, potestates contrarias debellaturus, advenit, ut nos ab utraque morte misericorditer liberaret, usque ad proprii sanguinis effusionem multiplicem et copiosam, insuper et usque ad mortem ignominiosam, tam fortiter agonizavit et vicit.

\section{APOLOGIA DE NATURA RERUM ET HISTORIA TEMPORUM}

Porro ipsam rerum naturam, quam diligentius ut potui descripsi, nullus (ut aestimo) superfluam aut inutilem reputabit, qui in ipso creaturarum libro nobis ad legendum proposito, creatoris, gubernatoris et conservatoris omnium Dei potentiam, sapientiam et bonitatem, ipsa veritate rationem illuminante, legere consueverit. Nam (ut ait magnus ille Basilius) $a b$ his qui veritatem intelligentes ex visibilibus invisibilia reputant, in terra et in aere, in aquis et in coelo, et in omnibus quae cernuntur, benefactoris monimenta certissima capiuntur. Sicque domino sensibus eorum ingiter adhaerente, nec peccatis tempus datur, nec inimico locus suggerendi contraria relinquitur. 
Es útil, pues, en esta obra anotar brevemente las épocas y los años de los reyes y emperadores, así como de los romanos Pontífices. $\mathrm{Y}$ anotar no sólo el momento histórico, sino el nombre de cualquier emperador, Papa, o rey, bajo el que se haya desarrollado, y que esté confirmado y reconocido: de modo que si, por ejemplo, existen dudas sobre una época, se pueda recurrir al catálogo de reyes de la región, en la que sucedió aquel hecho, y allí se encuentre en qué tiempo reinó aquel rey, y saber por ello en qué momento sucedió.

Como en Historia hay gran desacuerdo en la numeración de los años, pienso que mejor no adherirse a ninguno de manera tajante y absoluta, sobre todo a la numeración de las Crónicas. No es tan importante saber el año, como la época y el emperador bajo cuyo mandato tuvo lugar el hecho anotado.

Piadosa consideración sobre las guerras de los paganos.

Por lo demás, por las guerras famosas acaecidas en el mundo entre los distintos reinos antes de la venida de nuestro rey pacífico, que predicó la paz a su pueblo, podrá el lector advertir con cuánto ardor tenemos que luchar contra los enemigos espirituales, por nuestra salud espiritual y por la gloria que nos está prometida, cuando aquellos, como infieles, desconocedores de esta gloria y esta salud, y abandonados a su suerte, lucharon tan duramente por conseguir o defender una salud sólo temporal y una gloria pasajera.

Por la incalculable mortandad humana de esas guerras, puede verse la severidad de Dios con los malos, permitiendo que en cada guerra perecieran, en cuerpo y alma, a manos de sus enemigos tantos miles de ellos y tantas multitudes innumerables, al considerarlos inútiles, como viles rebaños, o despreciables por culpa de sus pecados.

Y se puede ver su bondad con los elegidos y su clemencia, por quienes el mismo Rey de Israel al final de los tiempos, mudado su hábito para que el enemigo no le reconociera, tomando forma de siervo, vestido con las armas de nuestra mortalidad, de modo que lo que es débil para Dios, fuera más fuerte para los hombres, vino al campo de batalla de este mundo a combatir a los poderes contrarios, y para librarnos con su misericordia de una y otra muerte, soportó con firmeza hasta morir la efusión múltiple y copiosa de su propia sangre, y venció.

\section{APOLOGIA DE LA NATURALEZA DE LAS COSAS Y DE LA HISTORIA DE LOS TIEMPOS}

Pienso que nadie estimará superflua o inútil la naturaleza misma de las cosas, que yo he descrito lo mejor que pude; nadie, digo, que iluminado por la verdad misma, esté acostumbrado a leer en el propio libro de la creación, puesto ahí para que lo leamos, el poder, la sabiduría y la bondad de Dios, creador, gobernador y conservador de todas las cosas. Pues, como dice el gran Basilio, Aquellos que entienden la verdad y por las cosas visibles deducen las invisibles, aprecian la obra de nuestro benefactor en la tierra, en el agua, en el aire, en el cielo, y en todo lo que ven. Así, unido estrechamente el Señor a sus sentidos, ni se les da ocasión de pecar, si se da lugar al enemigo para que sugiera cosas contrarias. 
Accedit ad haec et utilitas alia Doctoribus et Praedicatoribus, cunctisque scripturarum sacrarum expositoribus minime contemnenda. Ut enim Augustinus dicit: reum ignorantia facit obscuras figuratas locutiones, cum scilicet ignoramus vel animantium vel lapidum vel herbarum naturas, aliarumque rerum, quae ponuntur plerumque in scripturis alicuius similitudinis gratia. Numerorum quoque imperitia multa facit in eis non intelligi mystice posita.

Iam vero quanta est pulchritudo etiam infima huius mundi, et quam grata rationis aspectui diligenter consideranti, non solum modos et numeros, et ordines rerum, quae per diversas mundi partes decentissime et ordinatissime collocantur, verum etiam volumina temporum, quae per decessiones atque successiones eorum iugiter explicantur, et morte nascentium distinguntur.

\section{Erigitur mens in Deum ex consideratione creaturarum.}

Ego quidem, ut taceam de mundis corde, quorum est proprium videre Deum et in ipso delectari. Ego inquam (ut verum fatear) licet peccator immundus, cuius nimium mens adhuc in foecibus carnis suae iacet, eiusdem sordibus obvoluta, quadam tamen spirituali suavitate in mundi creatorem ac rectorem afficior, quia ipsum maiori veneratione ac reverentia prosequor, cum ipsius creaturae magnitudinem simul et pulchritudinem eiusque permanentiam intueor. Ipsa namque mens, plerumque paululum a praefatis cogitationum et affectioum faecibus se erigens, et in speculationis lucem (ut potest) assurgens, quasi de quodam eminenti loco totius mundi magnitudinem uno ictu considerat, infinita loca diversis creaturae generibus repleta intra se continentem.

Aevum quoque totius mundi, videlicet a principio usque nunc, quodam aspectu nihilominus conspicit: ibique tempora omnia per diversas generationum successiones rerum mutationes continentia, quasi sub quadam linea comprehendit. Et inde, saltem intuitu fidei, ad cogitandum utcumque Creatoris ipsius magnitudinem atque perpetuitatem ascendit.

Mundus in quo imitarur creatorem. Ipse namque mundus spaciositate locorum imitatur pro modulo suo Creatoris immensitatem. Varietate specierum ipsius pulchritudinem, prolixitate temporum eius aeternitatem. Haec autem ipsa temporalis pulchritudo, quae rerum transitu ac successu peragitur, historica narratione comprehenditur, quae ab initio mundi usque ad finem hoc opere describitur plenissime.

\section{APOLOGIA DE UNIVERSITATE SCIENTIARUM}

Si quis autem praesumptionis me velit arguere, quod ego (non dicam in omni facultate vel arte, sed nec, in una quidem satis edoctus) ausus sim etiam huic operi divisiones omnium scientiarum et artium, materiamque et ordinem singularum tam diligenter inserere, audiat iterum me non per modum auctoris, sed excerptoris ubique procedere, nec circa difficultates quarumlibet artium enuncleandas propositum meum instituisse, sed levia quaedam et plana de singulis memoriaeque utilia sub brevitate quadam, ut caetera posuisse.

In quibus etsi forsam aliqua sunt, quae non multum expediat scire, quandoque tamen haec ipsa turpe est ignorare. Et quia succedentibus facile de memoria elabuntur, mihi quidem visum est etiam horum memoriale quoddam compendiosum inter caetera, quae hoc opere continentur, ordine congruo ponere; ad quod pro loco et tempore oportuno studiosi lectoris animus valeat recurrere. 
Añádese a esto otra ventaja nada depreciable para los doctores, los predicadores, y todos los que explican las Sagradas Escrituras; y es que, como dice S. Agustín, la ignorancia de las cosas hace oscuro el lenguaje figurado, cuando por ejemplo desconocemos la naturaleza de los animales, de las piedras, de las plantas, o de otras cosas que se ponen en las Escrituras para hacer alguna comparación. Y el desconocimiento de los números hace también que no se entiendan muchas cosas puestas en ellas simbólicamente.

¡Cuánta es la belleza, incluso la más pequeña de este mundo, y qué grata es de ver para el que considera con atención no sólo los modos, los números y los órdenes de las cosas, repartidas oportuna y ordenadamente por las distintas partes del mundo, sino los círculos de los tiempos, que se explican por la desaparición y aparición continua de aquellas, y que se distinguen por la muerte de los que nacen!

La mente se eleva a Dios desde la contemplación de las criaturas.

Sin hablar de los limpios de corazón, de quienes es propio ver a Dios y gozarse en él, yo, a decir verdad, aunque pecador inmundo, cuya mente reposa aún demasiado en las heces de su propia carne, envuelta en su misma suciedad, me deleito con alguna dulzura espiritual en el creador y gobernador del mundo, porque lo sigo con mayor veneración y reverencia, cuando veo la grandeza y la hermosura de su criatura y su permanencia. La propia mente cuando se aparta un poquito de las mencionadas heces de los pensamientos y afectos, y se eleva, como puede, a la luz de la contemplación, como desde un lugar elevado, entiende en un momento la magnitud de todo el mundo, que encierra dentro de sí infinitos lugares, llenos de tan distintas clases de criaturas.

Ve también de alguna forma el tiempo de todo el mundo, desde el principio hasta ahora; y entonces comprende, como en una línea, todos los tiempos que contienen las mutaciones de las cosas por sucesión continua de las generaciones. Luego, con los ojos de la fe al menos, se eleva a considerar la grandeza del propio Creador, su belleza y eternidad.

\section{El mundo imita al Creador.}

El propio mundo imita con la amplitud de sus espacios la inmensidad del Creador; con la variedad de sus especies, su hermosura; y con la duración de su tiempo, su eternidad. Y esta misma belleza temporal, que surge con el paso y la sucesión de las cosas, se encierra en la narración histórica, que se hace en este libro plenamente desde el principio del mundo hasta el fin.

\section{APOLOGIA SOBRE LA UNIVERSALIDAD DE LAS CIENCIAS}

Si alguno quiere acusarme de presunción, porque yo (que tan poco versado estoy, no ya en todas las disciplinas o artes, sino ni en una sola) haya osado establecer con tanto cuidado en esta obra las divisiones de todas las ciencias y artes, y el orden y contenido de cada una de ellas, oiga otra vez que en todo momento he obrado no como autor, sino como recopilador; y que no he tenido el propósito de profundizar en las dificultades de cualesquiera artes, sino que algunas cosas ligeras, llanas y útiles a la memoria, las he expuesto como las demás, con una cierta brevedad.

Entre ellas, si es que hay algunas que no importa mucho conocer, está feo, sin embargo, que se desconozcan. Y como a los sucesores se les borra fácil de la memoria, me pareció prudente poner con un orden congruente un cierto memorial de ellas, que fuera, entre todo lo que que hay en esta obra, como un compendio de las mismas, para que el lector interesado pueda recurrir a él en el momento y lugar oportunos. 
Ad hoc autem ipsum nostrorum studiis provocatus sum, Isidori videlicet Hispalensis, et Hugonis, atque Richardi Parisiensis. Quorum primus in libro etymologiarum inter caetera de quibus agit, etiam de unauaque scientia pauca breviter tangit. Secundus in libro didascalicon scientiam generaliter dividit; singularumque materiam breviter describit. Et tertius (qui sic dicitur) in libro excerptionum idem facit.

Verum quoniam omnes hi de singulis transeundo brevissime tangunt, hac de causa etiam ad libros Philosophorum diverti, qui de his omnibus latius et diffusius agunt; indeque pauca notabilia breviter excerpsi, quae praedictorum catholicorum dictis (ut potui) competenter adieci.

Arti famulatur Theologia.

Accedit ad hoc quod omnes artes divinae scientiae tanquam reginae famulantur; unde illae quae liberales vocantur, plerumque in assertione ecclesiastici dogmatis assumuntur. Hinc beatus Petrus Apostolus in epistola quadam, itinerario Clementis adiuncta, sic loquitur: Cum, inquit, ex divinis scripturis integram quis et firmam regulam susceperit veritatis, absurdum non erit, si aliquid etiam ex eruditione ac liberalibus studiis, quae forte in pueritia attigit, ad assertionem veri dogmatis conferat. Ita tamen ut ubi vera didicit, falsa et simulata declinet.

\section{APOLOGÍA DE DICTIS PHILOSOPHORUM ET POETARUM}

Ne quis autem redarguendum me putet, eo quod multa de Gentilium Philosophorum, scilicet Poetarum libris, nonnulla etiam de quibusdam apocryphis in hoc opere posuerim: alioquin et Apostolos redarguere poterit, qui ex utroque genere nonnulla in epistolis suis testimonia usurpaverunt. Nam, verbi gratia, Paulus in epistola ad Corinthios Menandri Comicis senarium posuit, dicens: Corrumpunt bonos mores colloquia mala. Idem ad Titum scribens Epimenidis Poetae versiculum inducit, dicens: Cretenses semper mendaces, malae bestiae, ventres pigri. Idem etiam apud Athenienses in Martis curia disputans Arati poetae testimonio utitur de Deo dicentis: Ipsius enim et genus sumus.

Hinc beatus Hieronymus cuidam huiscemodi calumniatori suo, videlicet magno oratori Romano per epistolam sic respondit: Quaeris, ait, cur in opusculis nostris saecularium interdum litterarum exempla ponamus, candoremque Ecclesiae Ethnicorum sordibus polluamus; responsum breviter habeto; nunquam haec quaereres, nisi te Tullius totum possideret; si scripturas sanctas legeres, et earum interpretes omisso Volcatio evolveres. Nam et in Moyse, et in Prophetarum voluminibus, et epistolis Pauli, quaedam de libris Gentilium assumpta sunt. In Deuteronomio quoque Domini voce praecipitur mulieris captivae radendum esse caput et supercilia, omnesque pilos et ungues corporis amputandos, et sic eam habendam coniugio. Quid ergo mirum si ego etiam sapientiam, propter eloquii venustatem et membrorum pulchritudinem de ancilla atque captiva Israelitem facere cupio? Et si quid mortiferum est idolatriae, vel voluptatis erroris et libidinum, praescindo et abrado; mixtusque purissimo corpori immaculatos domino Sabaoth filios ex hac genero? Haec Hieronymi sunt. 
Me llevó a esto mismo el estudio de los nuestros, Isidoro de Sevilla, Hugo y Ricardo de París. El primero, en el libro de las Etimologías, amén de otras cosas, dice algo breve sobre cada una de las ciencias. El segundo, en su libro Didascalicon divide la ciencia de un modo general, y describe brevemente la materia de cada ciencia. Y el tercero (que así es llamado) hace lo mismo en su libro de Selecciones.

Todos ellos hablan como de pasada de cada cosa; por eso acudí también a los libros de los filósofos, que tratan de ellas con mayor amplitud y profundidad. De éstos saqué resumidas algunas notas importantes, que añadí como pude a los dichos de los mencionados católicos.

El arte sinve a la Teología.

A esto se añade que todas las artes sirven a la ciencia divina como a su reina, por eso las llamadas artes liberales muchas veces son asumidas en la afirmación de un dogma eclesiástico. De ahí que el apóstol S. Pedro en una carta unida al Itinerario de Clemente dice así: Cuando alguien toma de las Escrituras una regla de verdad integra y firme, no será absurdo que para afirmar el dogma verdadero añada algunas cosas de su erudición y de los estudios liberales que tuvo quizás en su niñez. Mas de forma que, cuando haya aprendido las verdaderas, abandone las falsas y simuladas.

\section{APOLOGÍA DE LOS ESCRITOS DE LOS FILÓSOFOS Y POETAS}

Si alguno piensa que se me ha de reprochar que haya puesto en esta obra muchas cosas de los libros de los gentiles, es decir, filósofos y poetas, e incluso de algunos libros apócrifos, deberá reprocharlo también a los apóstoles, que en sus epístolas tomaron algunos testimonios de unos y de otros. Por ejemplo, Pablo en su carta a los Corintios aprovecha un senario del cómico Menandro cuando dice: Las malas conversaciones corrompen las buenas costumbres. Y escribiendo a Tito toma un verso del poeta Epiménides que dice: Son los cretenses siempre mentirosos, malignas bestias, vientres perezosos. Igualmente, discutiendo en la curia con los atenienses, se vale de un testimonio del poeta Arato, que dice sobre Dios: También nosotros somos de su linaje.

Por eso S. Jerónimo, contesta así a un detractor suyo, gran orador romano: Preguntas, dice, por qué en mis escritos traigo de vez en cuando ejemplos de los gentiles, y deshonro el candor de la Iglesia con las impurezas de los paganos. Te lo diré brevemente. No harias esas preguntas, si no te poseyera por completo Tulio, si leyeras las Sagradas Escrituras y consultaras a sus intérpretes, exceptuando a Volcacio. Pues en Moisés, y en los libros de los profetas, y en las cartas de S. Pablo se toman algunas cosas de los libros de los gentiles. También en el Deuteronomio se pone en boca del Señor que a la mujer cautiva se le raerá el cabello y las cejas, y se depilará el cuerpo y cortará las uñas, y estará asi dispuesta para el matrimonio. ¿Qué tiene de extraño que yo quiera hacer a la sabiduria, de sierva y cautiva, israelita, por la gracia de su palabra y la belleza de sus formas, y si hay algo que puede llevar a a idolatría, al placer o a la pasión, lo corte y lo elimine, y que unido a su cuerpo purísimo engendre yo para el Señor Sabaoth hijos inmaculados? Hasta aquí S. Jerónimo. 
Ego quidem non ignoro Philosophos inter se multa dixisse contraria, maxime de rerum natura. Verbi gratia, aerem quidam naturae calidae esse posuerunt, ut Aristoteles et Avicenna. Quidam vero gelidae; ut Seneca. Venena quoque serpentum, quidam frigida esse dicunt; ut Isidorus: quidam vero calida; ut Avicenna. Sed quoniam in istis, et in aliis huiusmodi utralibet pars contradictioni absque fidei nostrae periculo potest credi vel discredi, lectorem admoneo ne forsan abhorreat, si quas huiusmodi contrarietates sub diversorum auctorum nominibus in plerisque locis huius operis insertas inveniat, praesertim cum ego iam professus sim in hoc opere me non tractatoris, sed excerptoris morem gerere, ideoque non magnopere laborasse dicta Philosophorum ad concordiam redigere, sed quantum de unaquaque re quilibet eorum senserit aut scripserit recitare, lectoris arbitrio relinquendo cuius sententiae potius debeat adhaerere.

Quia vero plerumque etiam Medici in medicinarum simplicium complexionibus, et qualitatum gradibus dissentire videntur, sciendum est, quod secundum diversitates regionum, etiam complexiones hominum et animalium caeterorumque terraenascentium variantur; ita ut aliqua eiusden generis res alicubi sit antidotum, et alibi venenum. Nam, verbi gratia, papaver nigrum in medicorum libris venenum esse scribitur, quod tamen apud nos in cibum assumitur. Sicut etiam extremitas caudae Cerviab Avicenna et Razi venenum esse computatur, quod a regionis nostrae militibus constanter negatur.

\section{APOLOGÍA DE APOCRYPHIS}

Quod autem superius dictum est de Gentilium libris, idem etiam dici potest de Apocryphis; cum enim neutri apud Christi Ecclesiam in auctoritate habeantur. Ex utrisque tamen (ut dictum est) quaedam ab Apostolis in novo testamento testimonia usurpantur, verbi gratia, de Magis Pharaonis loquens Paulus ad Tim0theum ita scribit: Quemadmodum Iannes et Mambres restiterunt Moysi, ita et hi (scilicet haeretici) resistunt veritati. Quae utique Magorum nomina non invenit Apostolus in divinis libris, sed Apocryphis, ut dicitur in glossa. Iudas quoque in Canonica sua de malis hominibus loquens, sic scribit: Prophetizavit et de his autem septimus ab Adam, Enoch, ... Qui tamen libri Enoch inter Apocrypha computantur?

Ne hoc dico, quod velim Apocryphis (quod nimiae praesumptionis esset) auctoritatem dare, sed quia licet (ut opinor) ea legere et etiam credere, quae non sunt contra fidem Catholicam, licet non habeant veritatis certitudinem. Quaedam enim reputantur Apocripha, quia veritati adversantur, ut sunt libri haereticorum. Quaedam vero, quia auctores eorum ignorantur, licet puram veritatem contineant, ut est Evangelium Nazaraeorum. Quaedam etiam, quia de veritate eorum dubitatur, ut est liber de ortu et infantia beatae Virginis Mariae, et liber de infantia Salvatoris; liber quoque de Assumptione beatae virginis.

Quorum etiam primum Hieronymus ad petitionem Heliodori episcopi scripsit, prout ipse narrationem de Ioachim et Anna, et de ortu Virginis se quondam adhuc adolescentulum in quodam libello legisse meminit. Haec ipsa tamen quae scribit nec vera nec falsa esse asserit, sed tantummodo, sive vera sive falsa sint, ea salva fide, ac sine periculo animae et audi, et legi posse ab his, qui credunt Deum haec omnia facere potuisse. 
Sé yo que los filósofos han dicho cosas contradictorias, sobre todo de la naturaleza de las cosas. V.gr. unos, como Aristóteles y Avicena, afirman que el aire es de naturaleza cálida; otros, como Séneca, que de fría. De los venenos de las serpientes, unos dicen que son fríos, p. ej. Isidoro; otros, como Avicena, que son calientes. Mas como en estas y otras cuestiones así, pueden creerse o no las dos versiones, sin peligro para nuestra fe, aconsejo al lector que si en muchos lugares de este obra encuentra insertas algunas contradicciones de esta clase, bajo nombres de distintos autores, no se alarme, cuando además he confesado que mi trabajo en esta obra es de recopilador, no de intérprete, y por ello no me he ocupado demasiado en buscar acuerdos entre los dichos de los filósofos, sino sólo de exponer lo que sobre cada tema sintió o escribió cada uno de ellos, dejando al arbitrio del lector a qué versión deba adherirse más.

Mas, como normalmente incluso los médicos parecen discrepar en cuanto a la composición de las medicinas elementales y en el grado de sus cualidades, conviene saber que según los distintos países varía la complexión de los hombres, de los animales y de otros elementos que nacen de la tierra, de modo que algo de la misma composición en unos sitios es antídoto y en otros veneno. Por ejemplo, la adormidera (papaver nigra) en los libros de medicina está recogida como veneno; nosotros, sin embargo, la tomamos en la comida. También la punta de la cola del Cerviab, que Avicena y Razi la tienen por veneno, y los médicos de nuestro país lo niegan siempre.

\section{APOLOGÍA DE LOS APÓCRIFOS}

Lo que antes se ha dicho de los libros de los gentiles, se puede también decir de los apócrifos, ya que ni unos ni otros tienen para la Iglesia de Cristo autoridad. Aunque de ambos, se ha dicho, toman los apóstoles en el nuevo testamento, algunos testimonios; por ej. Pablo, cuando escribe a Timoteo sobre los magos del Faraón, dice: Así como Jannes y Mambres resistieron a Moisés, del mismo modo éstos (los heréticos) resisten a la verdad. Estos nombres de magos no los saca el apóstol de los libros sagrados, sino de los apócrifos, como se dice en la glosa. Y Judas en su carta canónica escribe: También profetizó de éstos Enoc, el séptimo desde Adán. Estos libros del Enoc se cuentan entre los apócrifos.

No digo esto yo porque quiera dar autoridad a los apócrifos, lo que sería demasiado presuntuoso de mi parte, sino porque se pueden leer, e incluso creer (pienso yo) aquellos que no van contra la fe católica, aunque no tengan fundamento de verdad. Algunos se consideran apócrifos porque se oponen a la verdad, como los heréticos. Pero otros, sólo porque se desconoce a sus autores, aunque contengan la verdad pura: como es el Evangelio de los Nazarenos. Y algunos, porque se duda sobre la verdad de lo que dicen: como el libro sobre el nacimiento e infancia de la Virgen María, y el de la infancia del Salvador, o el de la Asunción de la santísima Virgen.

El primero de estos, además, lo escribió Jerónimo a petición del obispo Heliodoro, según la narración que él mismo recordaba haber leído en un librito, siendo aún joven, sobre Joaquín y Ana y sobre el nacimiento de la Virgen. Sin embargo, esas cosas que escribe no asegura él que sean ciertas o no; sólo que, sean verdaderas o falsas, pueden oírlas o leerlas, quedando a salvo la fe, y sin peligro de su alma, aquellos que creen que Dios pudo muy bien haberlas hecho. 
Sic et ego pauca illa de Apocryphis huic operi inserui, non vera vel falsa esse asserendo, sed tantum ea quae legi simpliciter recitando, quae salva fide possunt, et credi, et legi. Neque enim aliter a quoquam Christiano libri Apocryphi, sive etiam Philosophici, vel Poetici legendi sunt, nisi in mente iugiter servando, quod dicit Apostolus: Omnia probate, quod bonum est tenete. Unde Hieronymus contra Vigilantium ita loquitur: Operis inquam, et studii mei est multos legere, ut ex plurimis diversos carpam flores. Nam tam omnia probaturus quam quae bona sunt electurus.

Scholium. Vide de hac re Institutiones Theologicas Io. Viguerii, De doctrinis et dogmatibus, aeconomiam. Ederi lib. 10, fol. 8 Et Gratianum a. 15. c. Sancta Roman. cuius verba adducuntur infra $c .13$.

\section{APOLOGf́ DE MODO EXCERPENDI DE QUIBUSDAM LIBRIS ARISTOTELIS}

Ego autem in hoc opere quorundam legentium animos refragari audio, quod nonnullos Aristotelis flosculos, praecipueque ex libris eiusdem Physicis et Mathematicis, (quos nequaquam ego ipse excerpseram, sed a quibusdam fratribus excerpta susceperam) non eodem penitus verborum schemate, quo in originalibus suis iacent, sed ordine plerumque transposito, nonnunquam etiam mutata perpaululum ipsorum verborum forma, manente tamen auctoris sententia, prout ipsa vel prolixitatis abbreviandae, vel multitudinis in unum colligendae, vel etiam obscuritatis explanandae necessitas exigebat, per diversa capitula inserui.

Quidam etenim (ut cum stomacho loquar) tam fideles et cauti verborum observatores existunt, adeoque fideliter ac syncere de quibuslibet libris sententias notabiles excerpi volunt, ut nec minimum iota de verbis ipsius auctoris, sive etiam de verborum ordine patiantur immutari; huiusmodi tamen cautelae districtionem patres nostros Doctores catholicos, nec in antiquorum flosculis excerpendis, nec in libris aliorum transferendis omnino tenuisse cognovi.

Cur Hieronymus non transtulit Hebraea de verbo ad verbum?

Verum ut istorum calumniis breviter respondeam; ut etiam de caeteris interpretibus, quos minus fideliter transtulisse constat, ad praesens taceam. Beatus certe Hieronymus eliquandae veritatis causa, divinas Scripturas ab Haebraico fonte quondam in Latini flumen eloquii transfundens, cuius editio merito in Ecclesia Christi prae caeteris omnibus dignitatem auctoritatis obtinuit, nequaquam tamen de verbo ad verbum transtulit, sed ex sensu sensum expressit, ut videlicet antiquae translationi (prout posset) salva veritate morem gereret. Neque ipsa eius translatio ab illa vulgata editione nimium discrepans, ipsa novitate verborum animos legentium insuetos offenderet. Nunquid igitur mendacii culpam incurrit, dum veritatem Hebraicam in Latinam transtulisse se dicit?

Caeterum quis tam fidelis diligensque relator est, ut eodem penitus verborum ordine narrationem aliquam referat, quo eam vel in libro legit, vel hominis cuiusquam relatu audivit? Aut nunquid falsitatis merito potest redargui, quia dicit: haec in illa historia legi, vel ab homine illo audivi, quamvis tamen in referendo non prosequatur penitus verborum ordinem, sed sententiam tenet? 
Así, también yo incluí en esta obra algunas cosas de los apócrifos, sin afirmar ni negar su veracidad, repitiendo sólo las cosas que he leído, y que pueden, quedando la fe a salvo, leerse y ser creídas. No de otro modo debe cualquier cristiano leer los libros apócrifos, o los filosóficos y poéticos, sino teniendo presente lo que dice el apóstol: Examinad, sí, todas las cosas, y ateneos a lo bueno. Por lo que Jerónimo escribe así contra Vigilantium: Corresponde a mi trabajo y a mi obra leer muchos libros, para sacar de muchísimos diversas flores Lo he de probar todo si he de elegir lo que es bueno.

Nota. Ver sobre esto: 'Institutiones Theologicae' Ioann. Viguerius; 'Oeconomia de doctrinis et dogmatibus' Eder. Lib. 10, fol 8; Gratianus a. 15. c. Sancta Romana, cuyas palabras se citan el cap. 13 .

\section{APOLOGía DEL MODO DE EXTRAER DE ALGUNOS LIBROS DE ARISTÓTELES}

Oigo yo que algunos lectores de mi obra están en contra de que haya incluido por algunos capítulos algunas sentencias de Aristóteles, sobre todo de sus libros de Matemáticas y Física (que no los extracté yo, sino que los tomé ya seleccionados por otros hermanos) sin respetar el mismo esquema de sus palabras, tal como están en el original, sino alterando normalmente el orden, incluso a veces cambiando un poco la forma de las mismas, respetando, eso sí, el sentido del autor, o porque era necesario abreviar lo muy prolijo, o reunir varias cosas en una, o por aclarar algún punto oscuro.

Hay algunos (lo digo con enfado) tan fieles guardianes y esclavos de las palabras, y quieren que las sentencias importantes se tomen de algunos libros tan fiel y escrupulosamente, que no permiten que se cambie ni una ' $i$ ' en las palabras de un autor, ni se altere nada en el orden de las mismas palabras. No sé yo que nuestros padres doctores católicos tuvieran una cautela así al recoger algunas sentencias de los antiguos, ni al traducir los libros de otros.

\section{¿Por qué Jerónimo no tradujo literalnmente del Hebreo?}

Mas, respondiendo brevemente a las calumnias de esos, para no hablar ahora de los demás intérpretes, cuyas traducciones consta que han sido menos fieles, S. Jerónimo, para esclarecer la verdad, al pasar las sagradas Escrituras de su fuente original hebrea al río de la lengua latina, cuya edición obtuvo merecidamente en la Iglesia de Cristo un grado de dignidad por encima de las demás, no tradujo en absoluto palabra a palabra, sino que del sentido expresó el sentido, siguiendo cuanto podía, y salvando la verdad, el modo de traducir antiguo; de manera que, no discrepando demasiado su propia edición de aquella obra divulgada, no ofendiera por la propia novedad de las palabras los ánimos desacostumbrados de los lectores. ¿Acaso es acusado de falsedad, cuando dice que ha pasado la verdad hebraica a la latina?

Además ¿qué narrador hay tan escrupuloso y fiel que cuente un hecho con las mismas palabras y en el mismo orden que las leyó en un libro o las oyó contar a alguien? ¿O es que se le puede acusar porque diga: esto lo leí en tal historia, o lo oí decir a tal señor, si al referirlo no lo repite con el mismo orden de palabras, aunque sí mantenga el mismo sentido? 
Sic ego, licet omnis re vera mendacii detestator, nec propriae quidem conscientiae stimulo remordente, nec illorum calumnia deterrente, et de flosculis Aristotelis, et de caeteris, quos in hoc opere per diversa capitula inserui et propriis auctorum nominibus annotavi, etsi forsam ex aliqua causarum praedictarum in plerisque locis aliquid immutaverim de superficie vel verborum ordine, audacter tamen, et scribam et dicam, hanc et illam sententiam illius auctoris esse, cuius scilicet nomen in titulo continetur.

\section{DE IMPARI AUCTORITATE EORUM, QUAE EXCEPTA SUNT}

\section{Primus locus datar Sacris Literis.}

Ex praedictis, itaque patet non omnia, quae in hoc opere continentur, paris auctoritatis esse, sed quaedam in eis supremum auctoritatis locum tenere, quaedam vero medium, et quaedam infimum, quaedam vero nullum, et in his omnibus excipio sacram paginam, olim a sanctis Prophetis et Apostolis, divina gratia indubitanter afflatis editam et scriptam, de qua in hoc opere nihil paenitus volui, propter ipsius usum communem, sed nec ausus fui, propter ipsorum sacrorum reverentiam excerpere, nisi fortiter percurrendo. Sicut enim Scriptura sacra praecedit alias tempore, sic etiam dignitate.

Denique in eius comparatione sacrorum doctorum quoque sequentium opuscula nullius auctoritatis esse testatur Agustinus in II contra Faustum disputatione, sic loquens: Sunt inquit libri, qui non praecipiendi auctoritate, sed proficiendi exercitatione conscribuntur a nobis. Inter hos enim sumus, quibus dicit Apostolus: Si quid aliud sapitis, id quoque vobis revelabit Deus. Quod genus litterarum non cum credendi necessitate, sed cum iudicandi libertate legendum est. Cui tamen ne intercluderetur locus, et adimeretur posteris ad quaestiones difficillimas tractandas atque versandas, linguae et styli saluberrimus labor, distincta est a posteriorum libris excellentia canonica auctoritatis veteris testamenti et novi, quae firmata Apostolorum temporibus per.successiones episcoporum, et propagationes ecclesiarum tanquam in sede quadam sublimiter collocata est. Cui serviar omnis fidelis et pius intellectus.

Ibi, si quid velut absurdum noverit, non licet dicere, auctor huius libri veritatem non tenuit, sed aut codex incorrectus est, aut interpres ipse erravit, aut tu non intelligis. In opusculis autem posteriorum, licet eadem inveniatur veritas, longe tamen est impar auctoritas. Unde nisi vel certa ratione, vel ex illa canonica auctoritate, quod ibi disputatum vel narratum est, demonstretur, si quis credere noluerit, non reprehenditur.

In ista vero canonica eminentia sacrarum litterarum, etiam si unus Propheta vel Evangelista obscurum aliquid in litteris suis posuisset, ipsa canonis confirmatione non declaratum, non licet dubitare quoniam verum sit, alioquin nulla erit pagina, qua humanae imperitiae regatur infirmitas, si librorum saluberrima auctoritas, aut contempta aboletur, aut interminata confunditur. Haec Augustinus. 
Así yo, que detesto de verdad toda mentira, sin remordimiento ninguno de conciencia, y sin temor a las calumnias de aquellos, de las flores de Aristóteles y de los demás que inserté por los diversos capítulos de esta obra, y que anoté con los nombres propios de sus autores, aunque quizás por alguna de las razones antedichas en muchos sitios he cambiado algo de la forma o el orden de las palabras, diré, sin embargo, y escribiré sin miedo que esta y aquella sentencia son de tal autor, cuyo nombre aparece en el título.

\section{DE LA DESIGUAL AUTORIDAD DE LOS TEXTOS SELECCIONADOS.}

\section{Ocupa el primer lugar La Sagrada Escritura.}

De lo dicho, queda claro que no todo lo que hay en esta obra tiene igual autoridad, sino que unos textos tienen la máxima, otros media, otros poca, y algunos carecen de ella. Entre todos ellos destaco especialmente la obra sagrada, escrita y editada por los profetas y los apóstoles, inspirados sin duda por la gracia divina, obra de la que no quise en mi trabajo extractar absolutamente nada, porque es de uso común; ni osé hacerlo (si acaso, algo breve) por respeto a los propios libros sagrados. Igual que estos libros preceden en el tiempo a los demás, también los aventajan en dignidad.

Afirma S. Agustín en su obra Contra Fausto (disput. 2) que, en su comparación, los escritos de los doctores sagrados y los posteriores no tienen ninguna autoridad: Hay libros, dice, que los escribo no por la autoridad de su contenido, sino por su utilidad. Yo soy de aquellos de los que dice el apóstol: Que si vosotros pensáis de otra suerte, Dios os iluminará también en esto. Estos escritos no han de leerse con la obligación de creerlos, sino con libertad de opinar. Mas, sin quitarles su lugar, ni privar a la posteridad de su trabajo saludable de lengua y estilo en el tratamiento y presentación de cuestiones difíciles, su autoridad es distinta de la autoridad canónica del antiguo y nuevo testamento, que fijada en tiempo de los apóstoles, a través de los sucesivos obispos y la propagación de las iglesias fue colocada de un modo sublime como en un trono, para que a ella se subordine todo intelecto piadoso y fiel.

Si alli se encontrara algo como absurdo, no vale decir: el autor de este libro no estaba en lo cierto, sino o bien que el códice está sin corregir, o que falló el intérprete, o que uno mismo no lo entiende. En los libros de autores posteriores, aunque se halle la misma verdad, su autoridad es muy distinta. Por eso, lo que en ellos se discute o se cuenta, si no está demostrado con un argumento firme o con aquella autoridad canónica, y alguien no lo quiere creer, no se le reprende.

Mas en esta canónica eminencia de las Sagradas Escrituras, si un profeta o un evangelista hubiera puesto en sus libros algo oscuro, no aclarado con la propia confirmación del canon, no se puede dudar que sea verdad. De lo contrario, si la autoridad más eminente de los libros se elimina despreciándola, o se toma por incompleta, no habrá una página en la que se pueda afianzar la inconsistencia de la ignorancia humana. 


\section{DE ORDINE DIGNITATIS EARUNDEM}

Secundus locus Canonibus Ecclesiae, Decretis Pontificum, et SS. Patribus tribuitur.

Exceptis igitur divinis libris, et in summa quadam auctoritatis arce sepositis, primum post eos locum tenent Epistolae decretales Romanorum Pontificum, et Canones generalium Conciliorum, opuscula quoque sacrorum Doctorum.

Nam in decretis Gratiani, in I par. 20 distin. Legitur: Epistolae decretales conciliorum canonibus, pari iure exequantur. Divinarum vero scripturarum tractatores, etsi scientia Pontificibus praemineant, tamen quia dignitatis eorum apicem adepti non sunt, in scripturarum quidem expositionibus eis praeponuntur, in causis vero diffiniendis ubi non solum scientia, sed etiam potestas requiritur, secundum post eos locum merentur, sicut auctoritas Leonis Papae huius nominis quarti probatur. Haec Gratianus.

Utrum ergo genus in primo auctoritatis gradu merito ponitur; quoniam ut excedentia et excessa sibi vicissim praeferuntur. Illos autem sacros Doctores in eo gradu ponere volui, qui auctoritate Romanae Ecclesiae canonizati sunt, et eorum libri per Concilia Pontificum approbati. Ut sunt Dionysius, Ignatius, Cyprianus, Hilarius, Athanasius, Basilius, Gregorius Nazianzenus, Ambrosius, Hieronymus, Ioannes Chrysostomus, Augustinus, Cyrillus, Fulgentius, Cassiodorus, Isidorus, et alii multi.

Medium vero locum tenent Doctores caeteri, prudentes quiden et Catholici, sed non Canonizati, ut Isichius, Beda presbyter, et Alcuinus Caroli magister, Rabanus, et Strabus eiusdem discipulus, Haymo, et Ivo Carnotensis, Richardus, et Hugo Parisiensis, aliique plurimi.

\section{Tertius locus Philosophis conceditur.}

Tertium autem et infimum tenent gradum Philosophi Doctoresque gentilium. Nam etsi Catholicae fidei veritatem ignoraverunt, mira tamen et praeclara quaedam dixerunt de Creatore et creaturis, de virtutibus et vitiis, quae et fide Catholica, et ratione humana manifeste probantur esse vera. Praeterea quoniam artifici cuilibet in sua facultate discentem oportet credere, secularium scientiarum studiosis scholaribus, ut in eis proficiant, necesse est primitus Philosophis earum inventoribus, vel peritis ac discretis tractatoribus fidem adhibere. Verbi gratia, Prisciano in grammatica, Aristoteli in logica, Tullio in rhetorica, Hippocrati in medicina.

Porro ea nullam inter caetera auctoritatis dignitatem habent quae sunt apocrypha, quorum, scilicet auctor penitus ignoratur, et de quorum veritate dubitatur. Itaque si quando legantur a quoquam, sive enarrentur, utrum credi vel non credi debeant, ipsius legentis vel audientis iudicio et voluntati relinquitur, sicut cum rumores aliqui, vel narrationes ignotae $a b$ illis plerumque, qui viderunt vel audierunt (ut assolet) referuntur.

Denique decretum Gelasii Papae, quo scripta quaedam approbantur, quaedam vero reprobantur, hic in ipso operis initio ponere volui, ut lector inter authentica et apocrypha discernere sciat, sicque rationis arbitrio quod voluerit eligat, quod autem noluerit relinquat. 


\section{DE SU GRADO DE DIGNIDAD}

El segundo lugar se atribuye a los Cánonesde la Iglesia, a los Decretos de los Pontífices y a los SS.

Padres. Aparte de los libros sagrados, puestos en el grado máximo de autoridad, el primer lugar después de ellos lo ocupan los Decretos de los Romanos Pontífices y los Cánones de los Concilios Generales; luego los escritos de los Doctores sagrados.

En los decretos de Graciano (part. I, distin. 20) leemos: Las cartas decretales de los concilios sigan con igual autoridad a los cánones. Los intérpretes de la Sagrada Escritura, aunque aventajen en ciencia a los Pontífices, sin embargo, como no tienen su misma dignidad, estarán por encima de ellos en la exposición de las Escrituras, pero en materia de fe, en que además de ciencia se requiere potestad, están detrás de ellos en autoridad, como queda establecido por la autoridad de León IV. Hasta aquí Graciano.

Unos y otros ocupan el primer grado de autoridad, pues alternativamente se dan la preferencia en ponerse y quitarse. He dado este grado de autoridad a los doctores sagrados canonizados por la autoridad de la Iglesia Romana, y cuyos libros han sido aprobados por los concilios de los Pontífices. Tales son Dionisio, Ignacio, Cipriano, Hilario, Atanasio, Basilio, Gregorio Nacianceno, Ambrosio, Jerónimo, Juan Crisóstomo, Agustín, Cirilo, Fulgencio, Casiodoro, Isidoro, y otros muchos.

Un lugar intermedio lo ocupan los demás doctores, prudentes y católicos, sí, pero no canonizados, como Isiquio, Beda presbítero, Alcuino, maestro de Carlos, Rábano, y Estrabo su discípulo, Haymo, Ivo Carnuntense, Ricardo y Hugo de París, y muchísimos más.

El tercer puesto se Asigna a los filósofos.

En tercer lugar están los filósofos y doctores de los gentiles, pues aunque ignoraron la verdad de la fe católica, dijeron cosas bellas y notables sobre el Creador y las criaturas, y las virtudes y los vicios; todas las cuales, según la fe católica y la propia razón humana, se ve claro que son verdaderas. Además, como se debe confiar en todo maestro que enseña su arte, los escolares que estudian las ciencias seculares, para progresar en ellas deben primero tener fe en los filósofos que las inventaron o en los peritos de las mismas, o en sus discretos intérpretes. Por ejemplo en Prisciano sobre Gramática, Aristóteles en Lógica, Tulio en Retórica, e Hipócrates en Medicina.

Entre los restantes, están los apócrifos, que no tienen autoridad ninguna, cuyo autor o es del todo desconocido o se duda de su verdad. Si alguien los lee o los refiere alguna vez, queda al criterio y decisión de quien los lee o los oye si debe o no creerlos; como cuando ciertos rumores o leyendas (lo que es muy frecuente) son contados por alguien que los ha visto $\mathrm{u}$ oído.

Por último, decidí poner aquí, al principio de la obra, el decreto del Papa Gelasio, en el que se aprueban unos escritos y se desaprueban otros, para que el lector sepa diferenciar bien los auténticos de los apócrifos, y a su criterio tome o deje lo que quiera. 


\section{DE LIBRIS AUTHENTICIS}

Sancta inquam Romana Ecclesia, nullis synodicis institutis caeteris eccesiis praelata, sed Evangelica voce Domini et Salvatoris nostri primatum obtinens, dicentis: Tu es Petrus, et super hanc petram aedificabo Ecclesiam meam. Post Propheticas, et Apostolicas, et Evangelicas scripturas, quas regulariter suscepimus, quibus Ecclesia catholica per gratiam Dei fundata est, has etiam suscipi non prohibet, videlicet sanctam Synodum Nicenam, mediante Maximo Constantino Augusto celebratam, in qua Arrius haereticus condemnatus est. Synodum Constantinopolitanam, mediante Theodosio seniore Augusto, in qua damnatus est Macedonius. Synodum Ephesinam primam, mediante Cyrillo Alexandrino episcopo, et Archadio episcopo ab Italia destinato, in qua Nestorius condemnatus est. Synodum Chalcedonensem, mediante Martiano, Augusto, et Anatholio Constantinopolitano episcopo, in qua Nestoriana, et Eutychiana haeresis simul, cum Dioscoro eiusque complicibus damnatae sunt.

Opuscula quoque Cypriani Carthaginiensis episcopi, Beati Basilii Capadocensis, Ioannis Constantinopolitani, Theophili Alexandrini, Hilarii Pictaviensis, Ambrosii Mediolanensis, Augustini Hipponensis, Hieronymi Presbyteri, Prosperi viri religiosissimi. Epistolam Leonis Papae ad Flavianum Constantinopolitanum episcopum.

Opuscula atque tractatus olim patrum orthodoxorum, qui in nullo a Sanctae Romanae Ecclesiae consortio deviaverunt, nec ab eius fide vel praedicatione seiuncti sunt, legenda decrevimus. Decretales quoque epistolas Romanorum Pontificum. Actus Sylvestri Papae: Vitas patrum Pauli, Antonii, Hilarionis, et omnium heremitarum, quas tamen Beatissimus Hieronymus descripsit.

Gesta quoque Sanctorum Martyrum, quae tamen secundum antiquam consuetudinem singulari cautela in Romana Ecclesia non leguntur: Nec vel levis subsanandi occasio in eo generetur, quia eorum nomina qui scripsere, penitus ignorantur a fidelibus: Aut superflua, aut minus apta, quam ordo rei fuerit, esse putantur, sicut cuiusdam Quirici, et Iulitae, et Georgii, aliorumque passiones, quae ab haereticis scriptae perhibentur. Nos autem omnes martyres, et eorum gloriosos agones, omni devotione veneramur.

Scriptura de inventione Sanctae Crucis, et alia de inventione capitis Ioannis Baptistae, novellae quidem revelationes sunt, et novelli eas Catholici legunt. Sed cum haec ad Catholicorum manus advenerint, Pauli Apostoli sententia praecedat: Omnia probate, quod bonum est tenete.

Item Ruffinus vir religiosus plurimos Ecclesiasticos libros edidit, et nonnullas scripturas interpretatus est Sed quia his eum Hieronymus in aliquibus de arbitrii libertate notavit, illa sentimus, quae eundem Hieronymum sentire cognoscimus. Non autem hoc solum dico de Ruffino, sed etiam de universis, quod idem vir de zelo Dei, et fidei reprehendit.

Origenis opuscula quoque nonnulla, quae idem Hieronymus non repudiat, legenda suscepimus. Reliqua omnia cum auctore suo dicimus esse renuenda. Eusebii Chronica, et eiusdem Ecclesiasticae historiae libros, quamvis in primo narrationis suae libro tepuerit, et post de laudibus et excusatione Origenis unum librum schismatice conscripserit, propter rerum tamen singularem notitiam, quae ad instructionem pertinent, usquequaque non dicimus renuendos. 


\section{DE LOS LIBROS AUTÉNTICOS}

La Santa Iglesia Romana, no puesta sobre las demás iglesias por ningún sínodo determinado, sino que tiene la primacía por la palabra evangélica de nuestro Señor Salvador, que dice: Tú eres Pedro, y sobre esta piedra edificaré mi Iglesia, después de los escritos de los profetas, los apóstoles y los evangelistas, que usamos regularmente, y con los que la Iglesia Católica fue fundada por la gracia de Dios, no prohíbe que se acepten también otros como el Sínodo de Nicea, celebrado bajo Máximo Constantino Augusto, en que fue condenado por hereje Arrio; el Sínodo de Constantinopla, bajo Teófilo Senior Augusto, en que se condenó a Macedonio; el primer Sínodo de Éfeso con los obispos Cirilo de Alejandría y Arcadio enviado de Italia, en el que fue condenado Nestorio; el Sinodo de Calcedonia, con Marciano Augusto y Anatolio obispo de Constantinopla, en que se condenaron las herejías Nestoriana y Eutiquia, junto con Dióscoro y sus cómplices.

También las obras de Cipriano, obispo de Cartago, del beato Basilio de Capadocia, de Juan de Constantinopla, de Teófilo de Alejandría, de Hilario de Poitiers, de Ambrosio de Milán, de Agustín de Hipona, del presbitero Jerónimo, y de Próspero, varón piadosísimo. Las cartas del Papa León a Flaviano obispo de Constantinopla.

Determinamos que se lean además los opúsculos y tratados de los en otro tiempo Padres ortodoxos, que en nada se desviaron del consorcio de la Santa Iglesia Romana, y no se apartaron de su fe y su predicación; las cartas decretales de los Romanos Pontífices. Las obras del Beato Silvestre, Papa; las Vidas de los Padres, Pablo, Antonio, Hilario, y de todos los eremitas, que escribió S. Jerónimo.

También las gestas de los santos mártires, aunque, según una antigua costumbre, por especial cautela no se leen en la Iglesia Romana, para que no se de la menor ocasión de enmendarlas, por no conocer en absoluto los fieles los nombres de quienes las escribieron. Se las considera superfluas, o menos importantes de lo que fueron en realidad, como las pasiones de un tal Quirico, de Julita, de Georgio, o de otros, que aparecen escritas por los herejes. Nosotros, no obstante, veneramos con gran devoción a todos los mártires y sus luchas gloriosas.

Los escritos sobre el hallazgo de la santa cruz, y sobre el de la cabeza de Juan Bautista son revelaciones muy recientes, y las leen los nuevos católicos. Mas cuando lleguen a manos de los católicos, tengan primero en cuenta el consejo del apóstol Pablo: Examinad, $s i$, todas las cosas, y ateneos a lo bueno.

También Rufino, hombre piadoso, editó muchos libros eclesiásticos e interpretó algunas escrituras; mas como $S$, Jerónimo le censuró en algunos de ellos por su libertad de juicio, sentimos lo que sabemos que sentía el propio S. Jerónimo. Y esto lo digo no sólo de Rufino, sino de todos aquellos a los que el mismo varón reprende sobre su celo de Dios y de la fe.

Consideramos que se pueden leer también algunos escritos de Origenes, que el mismo S. Jerónimo no rechaza. Los demás hay que rechazarlos junto con su autor. Las crónicas de Eusebio y sus libros sobre historia eclesiástica, aunque en el libro primero de su narración estuvo algo frio, y después escribió cismáticamente un libro de alabanzas y exculpación de Origenes, sin embargo por la importancia especial de los temas relativos a la instrucción, no decimos que haya que rechazarlos del todo. 
Orosium virum eruditissimum collaudamus, quia valde uberem, et necessariam, contra Paganorum calumnias, historiam ordinavit. Sedulii Paschale opus insigni laude praeferimus. Iuvenci quoque laboriosum opus non spernimus, sed miramur.

\section{DE LIBRIS APOCHRYPHIS}

Caetera vero quae ab haereticis vel schismaticis conscripta sunt, nullatenus recipit Catholica et Apostolica Romana Ecclesia, e quibus quaedam, quae ad memoriam venerint, et a catholicis vitanda sunt credimus esse subdenda.

Ariminensem Synodum a Constantio Caesare, Constantini filio congregatam, et nunc, et usque in aeternum confitemur esse damnatam. Itinerarium nomine Petri Apostoli, quod appellatur sancti Clementis, apocryphum est, in libris octo. Evangelia similiter nomine Petri. Iacobi, Bartholomaei, Thomae, Matthiae, Barnabae; Evangelia quoque quae falsarunt Lucianus, et Ifichius. Item actus nomine Petri, Andreae, Philippi, Thomae. Liber de infantia Salvatoris, et de Maria vel obstetrice. Liber qui dicitur pastoris. Liber qui dicitur fundamentum. Libri omnes Lucii discipuli diaboli.

Liber qui appellatur thesaurus. Liber de filiabus Adae vel Genesis. Actus Teclae et Pauli. Liber nepotis. Liber Proverbiorum, qui est ab haereticis conscriptus, et Sancti Sixti nomine praenotatus est. Revelationes Pauli, Thomae, Stephani. Transitus Sanctae Mariae. Poenitentia Adae. Testamentum Iob. Poenitentia Origenis. Poenitentia Cypriani. Liber Diogenis nomine gigantis. Liber Iannae et Mambrae. Liber qui dicitur Physiologus, Ambrosii nomine signatus, sed ab haereticis conscriptus. Liber qui dicitur sors Apostolorum: Centimetrum de Christo virgilianis versibus compaginatum. Historia Eusebii Pamphili. Opuscula Tertulliani, Lactantii Aphicani, Priscilae et Maximillae alterius Clementis Alexandrini, Tarsi Cypriani, Arnobii, Tyconii, Cassiani Galliarum presbyteri, Victorini Pictaviensis. Epistola Iesu ad Abagarum regem. Et epistola Abagari ad Iesum. Passio Cyrici, et Iulitae, et Georgii. Liber qui dicitur contradictio Salomonis. Liber quoque Symonis Magi, Nicolai, Corinthii, et Marcionis, Basilidis, Ebionis et caeterorum haereticorum, quos cum eorum auctoribus auctorumque subsequacibus, sub anathematis indisolubili vinculo confitemur esse damnatos in aeternum.

Hucusque decretum Gelasii Papae. Numerum autem, et nomina librorum, cuiusque Doctoris Catholici quae reperire potui, inferius iuxta ordinem historiae temporum quibus floruerunt, locis congruis annotavi.

\section{CONTINENTIA TOTIUS OPERIS}

Totum igitur opus istud summatim continet. Primo quidem de trino et uno Creatore omnium breve tractatum. Deinde de Coelo empyreo, et natura Angelorum. De statu quoque et ordine bonorum, et ruina maliciaque superborum. Post hoc de materia informi, et de fabrica mundi, ac iuxta seriem operum sex dierum de natura et proprietatibus singularum per ordinem rerum. Deinde vero de conditione hominis primi. De natura ac viribus animae, et sensibus, et partibus ac proprietatibus corporis humani; de requie Dei, et modo operandi; de primo statu Protoplasti et felicitate Paradisi; de lapsu hominis ac poena multiplici; de peccato in genere multiplicique peccati divisione ac singulorum generum proprietate. Postmodum vero de hominis lapsi 
Elogiamos a Orosio, hombre eruditismo, que escribió una historia muy fecunda y útil contra las calumnias de los paganos. Destacamos la obra admirable de Sedulio Paschale carmen; y no olvidamos, sino que elogiamos, la elaborada obra de Juvenco.

\section{DE LOS LIBROS APÓCRIFOS}

Los demás libros escritos por herejes o cismáticos de ningún modo los acepta la Iglesia Romana Católica y Apostólica; de ellos creemos que hay que señalar algunos que me vinieron a la memoria, y que los cristianos deben evitar.

Declaramos que ahora y siempre debe ser condenado el Sinodo Ariminense, convocado por Constancio César, hijo de Constantino. Son apócrifos los ocho libros del Itinerario de Pedro Apóstol, llamado de S. Clemente; los Evangelios de Pedro, Santiago, Bartolomé, Tomás, Matías y Bernabé; también los Evangelios que falsearon Luciano e Isiquio; los Hechos de Pedro, Andrés, Felipe y Tomás; el libro sobre la infancia del Salvador, y sobre Maria o la comadrona; el libro llamado del pastor; el llamado 'Fundamento'; y todos los libros de Lucio, discípulo del diablo.

Además, el libro titulado Tesoro; el libro sobre las hijas de Adán, o del Génesis; los Hechos de Tecla y Pablo; el libro del nieto; el libro de los Proverbios, escrito por herejes y titulado con el nombre de San Sixto; las Revelaciones de Pablo, Tomás y Esteban; el Tránsito de Santa Maria; la Penitencia de Adán; el Testamento de Job; la Penitencia de Origenes; la Penitencia de Cipriano; el libro de Diógenes de nombre Gigante; el libro de Jannes y Mambres; el libro titulado 'El Físico' signado con el nombre de Ambrosio, pero escrito por herejes; el libro titulado El destino de los Apóstoles; 'Centimetro' sobre Cristo, compaginado con versos de Virgilio; Historia de Eusebio Pámfilo; Escritos de Tertuliano, de Lactancio Africano, de Priscila y Maximila, de un segundo Clemente de Alejandría, de Tarso Cipriano, de Arnobio, de Ticonio, de Casiano presbitero de las Galias, de Victorino de Poitiers; Carta de Jesús al rey Abagaro y carta de Abagaro a Jesús; la Pasión de Cirico, Julita y Jorge; el libro titulado La Contradicción de Salomón. También el libro de Simón Mago, de Nicolás, de Corintio, de Marción, de Basilides, de Ebión, y de los demás herejes. A todos estos libros, con sus autores y sus secuaces, los condenamos para siempre con la pena indisoluble de la excomunión.

Hasta aquí el decreto del Papa Gelasio. El número y título de los libros de cualquier doctor católico que pude encontrar, los anoté después en sus lugares correspondientes, siguiendo el orden cronológico del tiempo en que aparecieron.

\section{CONTENIDO DE TODA LA OBRA}

De modo sumarial, este es el contenido total de la obra: Primero, un breve tratado sobre el Creador, uno y trino, de todas las cosas. Luego, del cielo empíreo y de la naturaleza de los ángeles: del estado y orden de los buenos, y de la ruina y malicia de los soberbios. Después, de la materia informe y la creación del mundo, siguiendo el orden de los seis días. A continuación, de la condición del primer hombre; de la naturaleza y potencias del alma, de los sentidos, y de las partes y propiedades del cuerpo humano; del descanso de Dios, y de su modo de obrar. Sobre el estado primero del primer hombre, y la dicha del paraíso. De la caída del hombre y su castigo múltiple. Del pecado en general, de la división múltiple del pecado, y de la propiedad de cada clase de pecados. Luego, de la 
reparatione; de proprietatibus fidei caeterarumque per ordinem virtutum; Donorum Spiritus sancti, atque beatitudinum.

De Numero quoque, et materia omnium scientiarum; post hoc autem iuxta seriem temporum, continet historiam rerum in mundo gestarum; dictorum memorabilium, ab initio saeculi usque ad tempus nostrum; Et primo quidem describit initium Ecclesiae, quod habuit ab Abel eiusque progressum per tempora Patriarcharum, iudicum, regum, ac ducum usque ad tempora Christi, et Apostolorum: iuxta ordinem sacrae historiae.

Multa etiam inferens utilia de gestis ac dictis Ethnicorum. Ex inde vero diffusius texit historias Ecclesiasticas per successiones Romanorum Imperatorum usque ad illum, qui nostris temporibus imperavit Fredericum. Inter haec autem ab initio commemorat singulorum temporibus suis ortus regnorum, successiones quoque Regum, et varios eventus bellorum. Errores Paganorum, Iudaeorum, Haereticorum. Gesta dictaque notabilia, atque librorum nomina Philosophorum et Poetarum.

Institutionem et formam, et efficaciam sacramentorum veterum ac novorum. Multiplicem Ecclesiae profectum ac varietatem temporum, numerumque et ordinem persecutionum eius, sub Imperio praecipue Romanorum per successiones Imperatorum. Gesta quoque laudabilia, et passiones, et miracula Sanctorum, scilicet Apostolorum, Confessorum, Martyrum, atque Virginum. Sed et actus memorabiles ac nomina librorum. Floresque non paucos Doctorum Catholicorum, Canones, et statuta Conciliorum et Romanorum Pontificum, Collationes et vitas Sanctorum Haeremitarum: regulas et instituta Sanctorum Patrum; initia quoque et profectus diversorum ordinum atque professionum.

Ad extremum vero de praesenti permixtione bonorum et malorum, et de vario statu animarum a corpore separatarum, de ordine saeculi futuri, de adventu et gestis Antichristi, de fine mundi, de die iudicii, de resurrectione mortuorum, et glorificatione Sanctorum, de suppliciis reproborum.

\section{DE QUADRIFARIA DIVISIONE TOTIUS}

Quoniam iam hoc ipsum opus, ob causam iam dictam superius, ad tantae magnitudinis immensitatem excreverat, ut in triplo (quemadmodum opinor) bibliothecae sacrae mensuram excederet, et per hoc sine labore vel sumptu nimio transcribi non posset, multorum rogatu fratrum intercedente, insuper et priore meo favente, mihique in remissionem peccatorum meorum pariter iniungente, ut totum opus abbreviando, in librum Manualem ad modum unius bibliae redigerem: hoc ipsum facere tentavi, ut potui. Sed nisi per nimiam longitudinem temporis, vel absque nimio dispendio vel depravatione ipsius operis implere non valui.

Qua propter ipsum opus universum in quatuor partes principales, tanquam in quatuor volumina perfecta, et a se invicem separata distinxi. Quarum una continet totam historiam naturalem. Alia vero totam seriem doctrinalem. Tertia vero totam eruditionem moralem. Quarta totam historiam temporalem. Prima siquidem prosequitur naturam et proprietatem omnium rerum. Secunda vero materiam et ordinem omnium artium. Tertia proprietates et actus omnium virtutum et vitiorum. Quarta seriem omnium temporum.

Siquidem et Plato (ut dicit Augustinus) perfecisse Philosophiam laudatur, quae in tres partes ab ipso distribuitur, unam videlicet naturalem, aliam rationalem, tertiam 
reparación del hombre caído; de las propiedades de la fe y de las demás virtudes por orden; de los dones y los gozos del Espiritu Santo.

Después, del número y materia de todas las ciencias. Sigue luego la historia de los hechos acaecidos en el mundo a lo largo de los tiempos; $y$ de los dichos memorables, desde el principio del mundo hasta nuestros dias. Se cuenta el principio de la Iglesia, que empezó con Abel y siguió con los Patriarcas, Jueces, Reyes y Jefes, hasta el tiempo de Cristo y de los apóstoles, siguiendo el orden de la historia sagrada.

Se incluyen también muchas cosas útiles de los hechos y dichos de los paganos. A partir de ahí, se van tejiendo las historias eclesiásticas de un modo más difuso, siguiendo las sucesiones de los emperadores romanos, hasta el que gobernó en nuestro tiempo, Federico. Se recuerda desde el principio la aparición de cada reino en su tiempo, la sucesión de los reyes, y varios episodios de guerras. Los errores de los paganos, de los judíos, de los herejes; hechos y dichos notables, así como los nombres de sus libros, de filósofos y poetas.

La institución, forma y eficacia de los antiguos y nuevos sacramentos. El provecho múltiple de la Iglesia y el cambio de los tiempos; el número y orden de sus persecuciones, sobre todo en época romana, bajo los distintos emperadores. Las gestas gloriosas, martirio y milagros de los santos: de los apóstoles, confesores, mártires y vírgenes. También los escritos memorables y el nombre de los libros. Y no pocas flores de los doctores católicos; cánones y estatutos de los concilios, de los pontífices romanos; las congregaciones y las vidas de los santos eremitas; las reglas e instituciones de los santos padres; los inicios y progresos de diversas órdenes y profesiones.

Finalmente, de la confusión actual de buenos y malos, de la distinta suerte de las almas separadas del cuerpo; de la otra vida; de la venida y obras del Anticristo, del fin del mundo; del día del juicio, de la resurrección de los muertos, la glorificación de los santos, y de los suplicios de los condenados.

\section{DE LA DIVISIÓN DE TODA LA OBRA EN CUATRO PARTES}

Como esta obra, por la razón que dije antes, había aumentado tanto, que triplicaba en extensión a la Sagrada Escritura, y no podía por ello transcribirse sin un esfuerzo y un gasto demasiado grandes, a petición de muchos hermanos, y aconsejado además por mi prior, que me proponía a la vez como penitencia para el perdón de mis pecados, que abreviando toda la obra la redujera al tamaño de un libro manual, como de una sola Biblia, intenté llevarlo a cabo, como pude. Pero no logré hacerlo, porque era demasiado el tiempo que eso requería y era excesivo el dispendio y la degradación de la propia obra.

Así pues, dividí la obra en cuatro partes principales, como en cuatro volúmenes completos e independientes entre sí. De ellos, uno contiene toda la historia natural; otro, todo lo doctrinal; el tercer volumen, la enseñanza moral; el cuarto, la historia temporal. En la primera parte se describe la naturaleza y propiedad de todas las cosas; en la segunda, el fundamento y orden de todas las artes; en la tercera, las propiedades y efectos de las virtudes y los vicios; y en la cuarta, la sucesión de todos los tiempos.

Se alaba a Platón, dice S. Agustín, por haber perfeccionado la filosofía, a la que dividió en tres partes, natural, racional y moral. Quizás quienes entendieron a Pla- 
moralem. Et fortasse qui Platonem acutius ac veracius intellexerunt, tale aliquid de Deo omnium Creatore, gubernatore, conservatore senserunt, ut in eo sit causa omnium naturarum, lumen omnium rationum, et finis omnium actionum. Sitque in illo et causa subsistendi, et ratio intelligendi, et ordo vivendi. Quorum videlicet trium unum pertinere videtur ad naturalem, alterum ad rationalem, tertium ad moralem.

Itaque si homo ita creatus est, ut per id, quod in eo praecellit, id est, unum verum optimum Deum, sine quo nulla natura subsistit, nulla doctrina instruit, nullus usus expedit. Ipse quaerendus est, ubi nobis secuta sint omnia. Ipse cernendus ubi nobis certa sint omnia. Ipse diligendus, ubi nobis recta sint omnia; Plato quippe Dei huius imitatorem, cognitorem, amatorem, dixit esse sapientem.

Ad haec itaque tria spectant tres prime partes huius operis, videlicet, naturalis, doctrinalis, et moralis. Porro quarta et ultima, videlicet historialis, licet ad Philosophiam directe non pertineat, eo quod singularia rerum gestarum tantum enarrat, de quibus, scilicet singularibus, secundum Aristotelem ars non est, plurimum tamen admirationis et recreationis, et utilitatis habet, ut iam superius ostensum est.

Hinc apparet Vincentium absolvisse hoc opus antequam evectus esset ad Episcopatum.

\section{DE MATERIA UNIUSCUIUSQUE PARTIS}

Igitur primae partis fundamentum est historia sacra ab ipso principio creationis rerum usque ad requiem sabbhati. Cui etiam interferuntur ea quae pertinent ad naturam coeli et mundi. Fundamentum secundae partis est hominis lapsi reparatio quantum ad intellectum. Et fundamentum tertiae partis, quantum ad affectum est hominis reparatio.

Quartae partis fundamentum est primo quidem sacra Scriptura a generatione primi hominis usque ad Imperium Neronis. Inde vero Chronica Eusebii, Hieronymi, Prosperi, Sigiberti, ac caeterorum Chronographorum, per successiones Imperatorum, usque ad diem istum. Cui videlicet universali historiae praeponitur brevis epilogus partis primae, et secundae ac tertiae: in medio vero locis congruis inseruntur divisiones terrarum ac gentium, testamenta Patriaecharum, ceraemoniae Iudaeorum, et sacramenta Christianorum, sed et variae intermiscentur historiae, prosequentes gesta, vel dicta notabilia Regum, Tyrannorum, Imperatorum, Philosophorum, caeterorum etiam virorum illustrium

Mutationes temporum, et varios eventus rerum, ut est lustini vel Pompei Trogi ${ }^{90}$, et historia Orosii, historia quoque Alexandri Magni, et Darii. Historia Iulii Celsi de bellis Caesaris. Et Suetonii historia de 12 Caesaribus. Historia Ecclesiastica Eusebii Caesariensis. Ruffini Aquilegiensis, et Hugonis Floriacensis. Historia quoque tripartita Cassiodori ${ }^{91}$ Historia Hieronymi et Heralidis, de gestis et dictis Patrum. Historia quoque Cassiani, de collatinionibus Patrum. Historia Turpini Remensis, de gestis Caroli Magni Imperatoris, caeterorumque multorum historiographorum. Adduntur et aliae etiam innumerabiles historiae breves, de passionibus Apostolorum et Martyrum, gestis ac moribus et conversatione Sanctorum Episcoporum, Monachorum, caeterorumque Confessorum. 
tón más profunda y verazmente refirieron todo aquello a Dios, creador, rector y conservador de todas las cosas, de modo que en él está la causa de las cosas naturales, la luz de todo entendimiento y el fin de todas las acciones; que se halla en él la razón de subsistir, la razón de entender, y el fin de la vida. De todo lo cual, lo primero se ve que atañe a la naturaleza, lo segundo a la razón, y lo tercero a la moral.

Si el hombre ha sido creado de forma que por lo que más destaca en él se acerca a aquello que aventaja a todo, esto es, al único y verdadero sumo bien, Dios, sin el que ninguna naturaleza subsiste, ni instruye ninguna doctrina, ni tiene utilidad ningún fruto, hemos de buscarlo a él, en quien tenemos seguras todas las cosas, y conocerlo a él, en quien tenemos la certeza de todo, y amarlo él, porque en él tenemos toda justicia. Al que así busca, y conoce, y ama a Dios, lo llama Platón sabio.

A estos tres apartados se refieren las tres primeras partes de esta obra, natural, doctrinal y moral. La cuarta y última, la historia, aunque no pertenece de suyo a la filosofía, porque sólo explica los hechos particulares de las cosas, sobre los cuales, es decir, los singulares, dice Aristóteles que no hay arte, tiene sin embargo gran interés, utilidad y atractivo, como antes se ha señalado.

Se ve por esto que Vicente acabó esta obra antes de ser nombrado Obispo.

\section{DEL CONTENIDO DE CADA PARTE}

La materia de la primera parte es la historia sagrada, desde el principio de la creación hasta el descanso del sábado, donde se incluyen cosas relativas a la naturaleza del cielo y del mundo. El fundamento de la segunda parte es la reparación del hombre caído, en cuanto al entendimiento. El de la tercera, su reparación en cuanto al afecto.

El contenido de la cuarta parte es, primero, la Sagrada Escritura, desde la formación del primer hombre hasta el imperio de Nerón. Siguen luego las Crónicas de Eusebio, Jerónimo, Próspero, Sigiberto, y de los demás cronistas, según la sucesión de los emperadores hasta ese tiempo. A esta historia universal la encabeza un breve resumen de la primera, segunda y tercera parte. En medio, se intercalan en lugares apropiados las divisiones de las tierras y las gentes, los testamentos de los Patriarcas, las ceremonias de los judíos y los sacramentos de los Cristianos; y se mezclan además diversas historias que cuentan hechos y dichos notables de reyes, tiranos, emperadores, filósofos, y otros hombres ilustres.

Alteraciones de los tiempos y sucesos varios, como los que cuenta Justino, o Pompeyo Trogo, la historia de Orosio, también la de Alejandro Magno, de Darío, la historia de Julio Celso sobre las guerras de César; la historia de Suetonio sobre los 12 Césares; la historia eclesiástica de Eusebio de Cesarea, la de Rufino de Aquilea, de Hugo de Florencia; la historia tripartita de Casiodoro93; la historia de Jerónimo y Heraclides sobre hechos y dichos de los Padres; la historia de Casiano sobre las congregaciones de los Padres; la historia de Turpino de Reims sobre las hazañas del emperador Carlo Magno; y las de otros muchos historiógrafos. Se añaden además innumerables historias breves sobre la pasión de los apóstoles y los mártires; sobre los hechos, costumbres y vida de los santos obispos, monjes y confesores. 
Inter haec etiam continet plurimorum flores librorum (ut dictum est) non tantum Sanctorum Doctorum, sed etiam Philosophorum et Poetarum. Veruntamen illorum, qui multa scripserunt ac magna, de quorum scriptis excerpseram plurima, ut Ambrosii, Hieronymi, Chrysostomi, Augustini, Gregorii, Bernardi, ac caeterorum huiusmodi.

Horum inquam flores causa vitandae prolixitatis in duas partes divisi. Nam illos quidem eorum libros, qui maxime sunt morales, ut est liber Confessionum Augustini, Meditationes Anselmi, vel beati Benardi, vel similes, sub quadam continuatione verborum abbreviavi, ita ut si libri cuiuslibet magnitudinem ignorantes, totum se habere putares, hos in quarta parte locis suis composui, ac per capitula distinxi, quatenus ad historiae modum, propter ipsam continuitatem, in refectoriis, in infirmatoriis, et aliis locis inter fratres aedificationis causa possint legi.

Caeteros autem flosculos, quos ex eisdem vel aliis libris minuatim, et incompactae per diversa loca excerpsi; in caeteris partibus sub diversis titulis congruenter inserere iudicavi; porro in fine quartae partis adiicitur epilogus brevis de fine mundi.

\section{XVIII. | RETRACTIO PRIMAE PARTIS}

\section{Excusat se de nonnullis.}

Tanto igitur, tamque loborioso opere per Dei gratiam in finem usque perducto, ego quoque mentem meam per spaciosissima Scripturarum maria iam ex longo tempore fluctuantem, ipsa distractione semetipsa quodammodo lacerantem ad portum stabilitatis suae reducere cupio. Quod utique dum per imbecillitatem conatus mei vix facio, serenato quodammodo libero rationis oculo hoc ipsum intuens, et in statera discretionis appendens, in parte quidem negligenter egisse, in parte vero modum excessisse reperio.

Itaque qui superius in excusatione mei multa dixisse recolo, ne tamquam humanae gloriae vanus appetitor, vitiorum meorum inveniar blandus palpator, improbusve defensor, sed magis meorum vitiorum in rationis libra districtus examinator, et acerbus malorum reprehensor, non erubescam in hoc operis principio culpam meam fateri, praesertim cum attestante Philosopho, nihil in humanis adinventionibus ex omni parte perfectum valeat inveniri.

Haec ergo in quibus, sicut nec ipse mihi complaceo, sic etiam Deo et Angelis, caeterisque quae ad theologiae materiam pertinent, ex diversis capitulis pauca capitula colligens, de singulis quaestionum articulis breviter ac succincte percurrendo transivi, quoniam de hac materia multa et varia scripta communiter a fratribus et aliis ubique haberi cognovi.

Porro investigando naturam, cuius notitia valet (ut supra dictum est) etiam ad expositionem sacrarum Scripturarum, non solum inquam in nostrorum libris, sicut Ambrosii, Basilii, Isidori, et aliorum quorumdam, verum in libris Philosophorum, videlicet, Aristotelis, Plinii, Solini, insuper et Medicorum, videlicet, Aesculapii, Hipocratis, Avicennae, Razi, Hali, Isaac, Constantini Platearii; dum non solum nostris, id est fratribus ordinis nostri, hoc ipsum opus desiderantibus atque poscentibus, caeterisque sanctarum Scripturarum expositoribus, sive Doctoribus, verum etiam quibusdam aliis, qui forsitam curiositate quadam sciendi incognita laborantes, talium notitia delectantur, satisfacere volui: fateor ex magna parte, meo 
Contiene flores de muchísimos libros, como se ha dicho, no sólo de santos doctores, sino también de filósofos y poetas. De los escritos de aquellos, que escribieron mucho y de gran importancia, saqué muchísimas notas: de Ambrosio, Jerónimo, Crisóstomo, Agustín, Gregorio, Bernardo, y otros así.

Las flores de estos, digo, para evitar la prolijidad, las ordené en dos grupos. Por una parte los libros sobre todo morales, como las Confesiones de S. Agustín, las Meditaciones de Anselmo, o de S. Bernardo, y similares; abreviados con sus mismas palabras. Si desconoces la extensión de algún libro y piensas que lo tienes todo, (observa que) los ordené en el cuarto volumen, en lugares apropiados, y los repartí por capítulos, para que entre los hermanos se puedan leer a modo de historia, dada su continuidad, en los refectorios, las enfermerías, o en otros lugares, para su edificación.

Las demás flores, que de éstos y de otros libros saqué en fragmentos pequeños y repartidos por distintos lugares, consideré oportuno incluirlos de forma congruente en los otros volúmenes bajo títulos diversos. Además, al final de la cuarta parte se añade un breve epílogo sobre el fin del mundo.

\section{XVII. |REVISIÓN DE LA PRIMERA PARTE}

\section{Se disculpa de algunas cosas.}

Llegada ya a su fin, gracias a Dios, esta obra tan grande y laboriosa, también yo deseo conducir al puerto de su descanso a mi mente, que ha vagado largo tiempo por los mares espaciosos de las Escrituras, y se ha lacerado a sí misma con esta misma distracción. Mientras lo consigo, cuando ya mis fuerzas se debilitan, viendo esta misma obra con el ojo sereno y libre, en cierto modo, de la razón, y poniéndola en la balanza de la discreción, encuentro por una parte que he obrado con negligencia, y por otra que he sobrepasado los límites.

Así pues, reconociendo que antes he dicho muchas cosas para excusarme, para que al buscar vanamente la gloria humana, no resulte un blando juez de mis vicios, o un defensor acérrimo, sino más bien un inspector justo en la balanza de la razón, y un duro censor de los males, no me ruborizaré en confesar al principio de esta obra mi culpa, sobre todo porque, como dice el filósofo: nada puede hallarse en las obras humanas perfecto del todo.

Esos temas, en los que yo me recreo menos, sobre Dios, los ángeles, y otros que pertenecen a la teología, resumiendo muchos capítulos en unos pocos, los abordé tratando de forma breve y sucinta cada apartado de esas cuestiones, porque supe que sobre esta materia había en todas partes muchos y variados escritos de nuestros hermanos y de otros.

Luego, investigando la naturaleza, cuyo conocimiento vale (como se ha dicho antes) para la exposición de las Sagradas Escrituras, no sólo en nuestros libros, p. Ej. Ambrosio, Basilio, Isidoro, y algunos otros, sino también en los libros de los filósofos, como Aristóteles, Plinio, Solino, y también de los médicos, como Esculapio, Hipócrates, Avicena, Razi, Hali, Isaac, Constantino Plateario, queriendo complacer no sólo a nuestros hermanos de orden, que deseaban y reclamaban esta obra, sino a los demás expositores de las Sagradas Escrituras, y doctores, incluso a algunos otros, que sufriendo quizás por la curiosidad de conocer lo desconocido, se deleitan con el conocimiento de tales cosas: confieso que en buena parte, es mi opinión, me excedí de los 
iudicio, professionis intentionis meae modum excessi, in illis praecipue investigandis ac describendis, quorum nomina in divinis libris non reperi. Itaque, dum curiosis morem gerere volui, vitium curiositatis incurri.

Etenim quod Medicorum est, promittunt Medici, tractant fabrilia fabri. Sic et ego tam sublimis professionis homunculus, cuius, scilicet, totum studium et labor debet esse circa lucrum animarum intendere, etiam in hoc opere debui, praecipue de his quae ad professionem meam spectant insistere.De caeteris autem praecipue, quae magis ad medicinam corporis pertinent, si forsitam inciderent (sicut Doctoribus nostris mos est) breviter pertransire.

Hoc est igitur, quod licet multis etiam a fratribus placeat, eo quod totum per quasdam rerum similitudines et integumenta figurarum ad aedificationem morum referri valeat. Super omnia tamen quae continentur in hoc opere mihi confiteor displicere. Non quod illa quidem in se bona non sint, taliumque studiosis utilia, sed quia professionem meam (ut dixi) non decuit huiuscemodi rebus investigndis ac describendis tam diligenter insistere.

\section{RETRATO SECUNDAE, TERTIAE, ET QUARTAE PARTIS}

Etenim in secunda parte, quasdam scientias vel artes diffusius prosequendo, vereor etiam aliquatenus modum excessisse. In tertia vero virtutes ac vitia describendo, non potui, ut iam supra dixi, omnium librorum moralium, etiam quos in promptu habebam, omnes flores in unum colligere. Sed de multis pauca pro modulo meo eligere, alioquin oporteret volumen in inmensum extendere. Porro in quarta parte, quamvis etaiam illic abbreviata sint omnia, propter magnitudinem tamen voluminis adhuc amplius institui minuendam: vellem (si fieri posset) de sanctorum miraculis rescidisse nonnulla.

\section{De miraculis paganorum nota.}

Denique si quis legentium, vel in prima, vel in secunda, vel in tertia, vel in quarta parte, de his quae forsitam requisierit, minus aliquid inveniat, necessitati abreviandi operis (ut iustum est) veniam concedat. Praeterea nullatenus lector abhorreat, si etiam in Gentilium historia videtur legi circa Paganos facta fuisse nonnulla miracula. Credibile enim est huiusmodi ostenta, nequaquam fuisse vera miracula, sed prodigiosa indicia, ipsosque daemones haec circa cultores suos fallaciter egisse, vel ostendisse. Quatenus eos huiuscemodi fallaciis in cultu suo facilius possent detinere.

Haec ad praesens de cunctis quae in ipso tanti operis initio dicenda erant, videlicet de causa et materia, et de titulo, et de modo agendi et utilitate, et calumniarum repulsione, et ipsius operis divisione atque retractatione, ad praesens sufficiant.

Hunc autem prologum propter causas praedictas a principio operis hucusque protractum, quia pari iure correspondet unicuique parti, totum in cuiuslibet parte inserendum iudicavi, ut simul cum totius partis capitulis adiunctis, locum suppleat unius libri. Et quia totum opus illud universale supradicta ratione Speculum maius decreveram appellare, his etiam quatuor eiusdem partibus, idem vocabulum per singulos titulos placuit annotare, ut videlicet prima vocetur Speculum naturale, secunda vero Speculum doctrinale, tertia quoque Speculum morale, quarta Speculum historiale. 
límites de mi profesión, sobre todo al investigar y describir aquellas cosas cuyos nombres no hallé en los libros divinos. Así, queriendo complacer a los curiosos, caí yo en el vicio de la curiosidad.

Lo que es de los médicos lo hacen los médicos, y el obrero trabaja en sus obras. Así yo, un hombrecito de profesión tan sublime, cuyo trabajo y dedicación completa debe ser atender la salud de las almas, también en esta obra debí principalmente insistir en lo que atañe a mi profesión, y las demás cosas, sobre todo lo relacionado con la medicina del cuerpo, si por casualidad se presentaban, debí pasarlas (como es costumbre en nuestros médicos) rápidamente.

Esto es lo que, a pesar de que a muchos hermanos les agrada, porque mediante algunas similitudes y velos de figuras puede referirse todo a la edificación de las costumbres, a mí, sin embargo, más me desagrada de cuanto hay en esta obra. Y no porque no sean cosas buenas en sí y útiles para los estudiosos de las mismas, sino porque a mi profesión no le compete insistir tanto en la investigación y descripción de este tipo de cosas.

\section{REVISIÓN DE I.A SEGUNDA, TERCERA Y CUARTA PARTE}

En la segunda parte, al exponer con demasiada profusión algunas ciencias o artes, temo haber sobrepasado un poco los límites. En la tercera, al describir las virtudes, no pude, como dije antes, reunir todas las flores de todos los libros morales, ni siquiera de los que tenía a mano; pero pude elegir, a mi criterio, de muchos, algunas pocas cosas. De otro modo tendría que ampliar el volumen hasta lo infinito. En la cuarta parte, aunque también allí todo está abreviado, por la excesiva extensión del volumen, decidí abreviar aún más. Querría haber eliminado, de serme posible, algunas cosas acerca de los milagros de los santos.

Sobre los milagros de los paganos.

Por último, si algún lector no encuentra en estas cuatro partes algo de lo que busca, discúlpelo por la necesidad de abreviar la obra hasta lo justo. Además, que no se extrañe el lector si en la historia de los gentiles le parece ver que también entre los paganos se hicieron algunos milagros. Hay que pensar que tales ostentaciones no eran en absoluto verdaderos milagros, sino señales prodigiosas, que hacían o mostraban los propios demonios entre sus adoradores, para retenerlos más fácilmente en su culto con esa clase de mentiras.

Por el momento, de cuanto había que decir al principio de una obra tan exten$\mathrm{sa}$, baste lo que hemos señalado de su causa y materia, del título y el modo de proceder, de su utilidad, del rechazo de las acusaciones, de la división de la obra y de su revisión.

Este prólogo, traído aquí del principio de la obra por las razones antedichas, pues corresponde por igual a cada una de las partes, creí oportuno incluirlo al principio de cada parte, para que unido con los capítulos correspondientes formara un libro único. Y como, por la razón que antes dije, había decidido llamar al conjunto de la obra Speculum Maius, quise emplear el mismo vocablo en los títulos de cada una de sus partes, de manera que la primera se llame Speculum Naturale, la segunda Speculum Doctrinale, la tercera Speculum Morale, y la cuarta Speculum Historiale. 


\section{CONTINUATIO QUATUOR PARTIUM AD INVICEM}

Sic igitur in hac prima parte totam naturalem historiam (ut supra dixi) auxiliante Deo, diversorum auctorum flosculos excerpendo, iuxta possibilitatis nostrae modulum breviter ad plenum prosecuti sumus, disserendo videlicet de natura divina, de Angelica creatura, de materia informi, de fabrica mundi, et iuxta seriem operum sex dierum, de proprietatibus naturalibus singularum per ordinem rerum.

Dehinc in secunda et tertia parte, de hominis lapsi reparatione, hoc est de his quibus a lapsu multiplici reparatum est genus humanum, scilicet de numero et materia omnium scientiarum, de proprietatibus singularum virtutum agere volumus, quatenus in hunc modum totius mundi plenius continentiam, omniumque rerum et artium atque virtutum summam sub quodam compendio memoriter teneamus.

Porro in quarta parte, simili modo temporalem rerum in mundo gestarum historiam, dictorum memorabilium ab initio saeculi usque ad finem, quae scripta reperimus, iuxta seriem temporum per ordinem generationum, regnorumque successionem, sicut in superiore praefatione totius operis praelocuti sumus, breviter ut potuimus percurrimus.

Veruntamen, quia sicut praedictum est, istae quatuor speculi partes diversae sunt, ac propter nimiam transcribendi sumptuositatem, alterm sine altera nonnulli habituri sunt, et in hac prima parte loco competenti totius ultimae partis materiam, id est totius historiae temporalis chronicam breviter perstrictam praelibabimus. In fine, videlicet ubi de temporibus agitur.

In ultimae quoque partis capite placuit quoddam historiae naturalis, et omnium artium atque virtutum ephitoma, id est recapitulationem brevem praemittere; quatenus unaquaeque pars caeteras utrimque contineat, omnesque se invicem complectantur.

Et quia totum opus primum, quod in quatuor ob sui magnitudinem est divisum Maius Speculum appellavimus, ideo primam istam partem, quae Speculum Naturale dicitur, a diversis mundi acceptionibus inchoamus. 


\section{RELACIÓN MUTUA ENTRE LAS CUATRO PARTES.}

Así pues, en esta primera parte hemos hecho un breve resumen de toda la historia natural, como dije antes, escogiendo, con la ayuda de Dios, diversas florecitas de distintos autores, tratando de la naturaleza divina, de los ángeles, de la materia informe, de la fábrica del mundo, y siguiendo las obras de los seis días, de las propiedades naturales de cada cosa por su orden.

En la segunda y tercera parte queremos tratar de la renovación del hombre caído, es decir, de todo aquello con lo que el género humano ha sido reparado de su caída múltiple, o sea, del número y materia de todas las ciencias, de las propiedades de cada una de las virtudes, de modo que en un compendio recordemos mejor el contenido de todo el mundo y la suma de todas las cosas, de las artes y de las virtudes.

Luego, en la cuarta parte, recorremos igualmente la historia temporal de lo acaecido en el mundo, de los dichos memorables desde el principio al fin del mundo, siguiendo cronológicamente las generaciones y la sucesión de los reinos, según hemos dicho en el prefacio anterior de toda la obra.

Mas como, según se ha dicho antes, estas cuatro partes del espejo son distintas, y por el gasto excesivo de transcribirlas algunos tendrán una y no otra, también en esta primera parte tocaremos ligeramente en su lugar apropiado la materia de toda la última parte, es decir, repasaremos, brevemente resumida, la crónica de toda la historia temporal. En su final, es decir, cuando se habla de los tiempos.

En el encabezamiento de la última parte creímos oportuno adelantar un epítome, o recapitulación breve de historia natural y de todas las artes y virtudes, de modo que cada parte contenga a su vez a las demás, y todas se contengan recíprocamente.

Y como al conjunto original de la obra, que debido a su extensión está dividido en cuatro partes, lo hemos llamado Speculum Maius, esta primera parte llamada Speculum Naturale la iniciamos partiendo de las diversas acepciones del mundo. 